
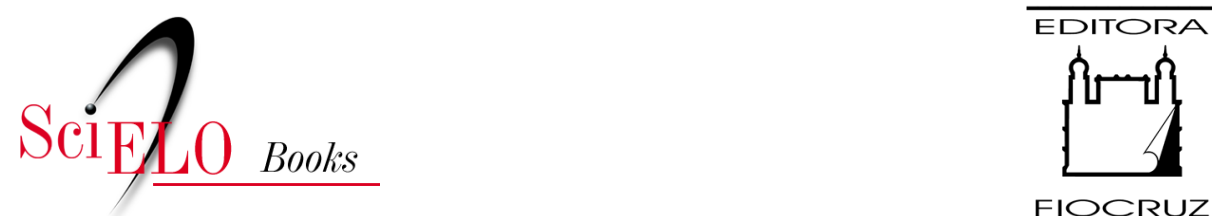

FIOCRUZ

\title{
3. Sistema de Atenção à Saúde
}

\author{
Lígia Giovanella
}

\section{SciELO Books / SciELO Livros / SciELO Libros}

GIOVANELLA, L. Sistema de Atenção à Saúde. In: Solidariedade ou Competição? Políticas e sistema de atenção à saúde na Alemanha [online]. Rio de Janeiro: Editora FIOCRUZ, 2001, pp. 97-138. ISBN: 978-65-5708-097-9. http://doi.org/10.7476/9786557080979.0006.

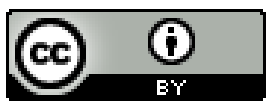

All the contents of this work, except where otherwise noted, is licensed under a Creative Commons Attribution 4.0 International license.

Todo o conteúdo deste trabalho, exceto quando houver ressalva, é publicado sob a licença Creative Commons Atribição 4.0.

Todo el contenido de esta obra, excepto donde se indique lo contrario, está bajo licencia de la licencia Creative Commons Reconocimento 4.0. 


\section{Sistema de}

O sistema de atenção à saúde na Alemanha caracteriza-se por completa separação entre o financiamento e a prestação. Enquanto o financiamento é predominantemente público, realizado por meio de contribuiçāo e afiliação compulsórias às provedoras autônomas do Seguro Social de Doença, as Krankenkassen, a atenção é ofertada por prestadores governamentais, privados e filantrópicos. É vetada, às Caixas, a prestação direta de serviços de saúde.

No setor hospitalar, a maioria dos prestadores é pública e a oferta no setor ambulatorial é quase exclusivamente privada, prestada em consultórios próprios por médicos credenciados. As Praxis - consultórios - são pequenas empresas privadas de caráter lucrativo, cuja prestação de serviços, tida como de interesse público, é regulada pelo Estado. $\mathrm{O} m i x$ público-privado no setor ambulatorial caracteriza-se por financiamento público, prestação privada dos serviços e regulação desta pelo Estado. No setor hospitalar, a regulação estatal exerce-se sobre a prestação pública, municipal e estadual, e privada; o financiamento das prestaçōes é encargo do GKV. ${ }^{107}$

Os consultórios médicos credenciados gerais ou especialistas săo a porta de entrada do sistema. A atenção hospitalar é condicionada ao encaminhamento pelo médico de consultório. Há estrita separação entre os setores ambulatorial e hospitalar. Os hospitais não prestam atenção ambulatorial nem especializada, tratando pacientes somente em regime de internação. A maioria dos médicos exerce atividade apenas em um dos setores: ou trabalha como assalariado em hospitais ou tem consultório próprio. ${ }^{108}$

107 Mesmo nos hospitais públicos, as prestaçōes são pagas pelas Caixas, seguros privados ou departamentos de Assistência Social dos municípios. Não existe assistência gratuita.

108 Contudo, alguns médicos de consultório acompanham seus pacientes durante as internações e, por vezes, médicos de hospital exercem atividades como especialistas autorizados. 


\section{Atenção Ambulatorial}

A atenção ambulatorial proporcionada pelo GKV distingue-se pela liberdade de escolha do médico por parte dos segurados, bem como por oferta constituída de modo exclusivo por médicos credenciados e por relaçōes da oferta e demanda reguladas mediante negociaçōes de grupo entre prestadores de serviços e provedoras de seguros sociais (Alber, 1992).

Pelo lado da demanda vige a liberdade de escolha e, pelo lado da oferta, o monopólio da corporação médica, afirmado por contrato de garantia da atenção médica ambulatorial efetuado entre Caixas e Associações de Médicos das Caixas (Kassenärztliche Vereinigung-Kven). A condução e regulamentação da atenção é feita, em negociações de grupo, por intermédio: das Kven, das Associações das Caixas e das associações conjuntas de médicos e Caixas (órgāos da administraçāo autônoma conjunta).

A liberdade de escolha dos médicos pelos segurados é ampla. A quase totalidade dos médicos em exercício da prática ambulatorial é credenciada pelas Caixas (97\%). O scgurado pode escolher qualquer médico credenciado, seja clínico geral ou especialista. Para consulta com especialistas, não é obrigatório o encaminhamento pelo clínico geral (Hausarzt). ${ }^{109}$

Até 1993 havia restrição à troca de médico cm curto espaço de tempo. Novo médico poderia ser escolhido apenas a cada três meses. A visita a outro profissional nesse período estava condicionada a encaminhamento do médico inicialmente procurado. Utilizavam-se autorizaçōes para atendimento médico.

Com a implantação do cartão magnético do scgurado, em 1994, esta barreira foi abolida. Desse modo, a introdução do cartão do segurado produziu aceleração da tendência, previamente cvidenciada, de utilização primária da atenção prestada por médicos especialistas, bem como redução drástica do número de encaminhamentos (DGB, 1996d). Mesmo assim, a maioria dos segurados tem clínico geral (Hausarzt), que é o mais procurado nos casos de doenças crônicas (Alber, 1992). Atualmente estão previstos incentivos aos segurados para a procura primária do Hausarzt.

Os médicos credenciados são profissionais autônomos em exercício da 'prática liberal' da medicina e prestam serviços em consultórios próprios. Os consultórios médicos apresentam características de pequenas empresas. A imagem do médico com seu estetoscópio e esfigmomanômetro desapareceu há muito. Grande parte dos procedimentos diagnósticos e terapêuticos ć efetuada no consultório, requerendo-se para tal pessoal mais qualificada. ${ }^{110}$

109 Os clínicos gerais sāo denominados Hausarzt, cuja tradução literal seria 'médico do lar'. 110 Os consultórios hoje ocupam por volta de quatro a cinco auxiliares, em geral, mulheres. 
O crescimento do pessoal empregado por consultório nos últimos anos está ligado à ampliação da capacidade técnica dos consultórios e do grau de especialização dos médicos. ${ }^{111}$ Consultórios melhor equipados têm, cm contrapartida, aumento da participação dos custos (de investimento e operacionais) no seu faturamento. Desde o início dos anos 70, a participação dos custos no faturamento dos consultórios médicos cresceu de forma constante, atingindo, em média, 59,2\% em 1994 (Gerlinger 1994; Alber, 1992; KBV, 1996).

$\mathrm{O}$ acesso a ações prestadas por outros profissionais de saúde e setores da atenção, com exceção da atenção odontológica e psicoterápica, está subordinado a prescriçōes médicas. A utilização primária de iniciativa de um segurado desencadeia uma série de ações e gastos subseqüentes ordenados pelos médicos credenciados. Eles prescrevem medicamentos, outros métodos terapêuticos c meios de ajuda, autorizam benefício-doença e tomam a decisão acerca da necessidade de internação, realizando encaminhamento de grande parte das internações hospitalares.

A ação dos médicos credenciados exercc forte influência sobre o desenvolvimento dos gastos totais em saúde. Estima-se que cerca de $70 \%$ dos gastos do GKV, incluídos os gastos do setor ambulatorial, são desencadeados pelos médicos credenciados (SVR, 1994), o que caracteriza a demanda por serviços de saúde como basicamente secundária ou induzida, ${ }^{112}$ isto é, não definida pelo paciente/ consumidor. Grande parte da prestação em saúde não decorrc, portanto, de demanda primária, mas é solicitada pelos próprios prestadores.

Associações nāo lucrativas de direito público, geridas autonomamente pelos médicos - as Associações de Médicos das Caixas - agrupam os médicos credenciados por regiōes e em nível federal. Essas organizações de afiliação compulsória têm a funçāo de representar os médicos junto às Caixas, negociar a remuneraçāo, receber os honorários e distribui-los a cada médico, conforme a participação no conjunto de serviços prestados.

As Associações de Médicos das Caixas são mandatárias, por lei, da incumbência de garantia da atenção médica ambulatorial. Um contrato exclusivo de garantia da atenção é cstabelecido entre as Caixas e as Associaçōes de Médicos das Caixas - Kven (SGB, 1993), por meio do qual essas associaçōes tornam-se detcntoras de monopólio da prestação ambulatorial. É vedada a prestação de serviços médicos diretamente pelas Caixas e restrita a possibilidade de prestação de ações ambulatoriais pelos hospitais.

11 O alto valor dos custos de instalação de consultório - em média, 300 mil marcos (1993) sinaliza bem a ampliação da capacidade técnica por consultório (Gerlinger, 1994).

$112 \mathrm{O}$ termo 'demanda induzida pelo prestador' foi cunhado por Evans (1974 apud Almeida, 1995). A "idéia central é que os médicos ajustam a demanda de serviços às suas necessidades de rendimento, pressupondo inclusive a indução de utilização de mais serviços adicionais" (Almeida, 1995:60). 
Por suas funçōes públicas, as Associações de Médicos das Caixas ocupam posição-chave na atenção à saúde da Alcmanha. São as únicas responsáveis pela atenção ambulatorial e coordenam as atividades dos outros prestadores de serviços, exercendo forte influência sobre a divisão de trabalho entre as diversas áreas de assistência à saúde (Backer et al., 1989).

\section{Oferta e produção de serviços}

Em 1996, havia na Alemanha 343.556 médicos, dos quais 279.335 em exercício da atividade profissional. Entre os médicos em exercício da clínica, $40 \%$ (112.660) atuavam no setor ambulatorial e 48\% (135.341) trabalhavam em hospitais. A distribuição de médicos entre os setores ambulatorial e hospitalar alterou-se nas últimas décadas. Com o aumento da tecnicidade da atividade médica, desde 1975, passou a atuar maior proporção de médicos no setor hospitalar em comparação ao setor ambulatorial (KBV, 1996).

$\mathrm{Na}$ prestaçāo de assistência no setor ambulatorial observaram-se nas últimas décadas, tendências: à especialização progressiva; à expansão da oferta, pois o número de médicos credenciados cresceu mais rápido que a quantidade de segurados; ao crescimento do volume de ações produzidas (impulsionadas pelo modelo de remuneração); à elevação dos gastos ambulatoriais per capita, paralela à estabilidade de sua participação no conjunto dos gastos do GKV.

\section{Médicos por habitante}

A relação de médicos por habitante na Alemanha, cotejando-se com outros países, é das mais altas. Em 1995, o número de médicos em exercício profissional por mil habitantes cra de $3,36 .{ }^{113}$ Todavia, a relação de médicos credenciados por habitantes não é alta. Somente médicos de consultório têm status de credenciados e, como menos da metade dos médicos exerce atividade em nível ambulatorial, esta proporção é menor.

Embora tenha aumentado progressivamente, a relação médicos credenciados por habitante na Alemanha situa-sc entre as menos elevadas, em comparação com outros países em que vigem sistemas de credenciamento, exceto a Grã-Bretanha. Como mostra a tabela a seguir, na Alemanha Ocidental havia 1,34 médicos credenciado por mil habitantes em 1994, enquanto estas taxas eram mais elevadas na França $(1,95)$, na Áustria $(1,87)$ e na Bélgica $(1,51)$. Na Grã-Bretanha, a disponibilidade de médicos credenciados por habitantes é das menores: representa a metade da Alemanha e menos de um terço da observada na França.

113 Se forem levados em conta todos os médicos registrados, a relação sobe para 4,09 médicos por mil habitantes. 
Tabela 7 - Médicos e médicos credenciados por mil habitantes. Países selecionados - 1994

\begin{tabular}{l|rrrr|c}
\hline & \multicolumn{4}{|c|}{ Médicos credcnciados/1.000 hab. } & Médicos/1.000 hab. \\
\hline País & 1980 & 1985 & 1990 & 1994 & 1994 \\
\hline Alemanha Ocidental & 0,97 & 1,10 & 1,19 & 1,34 & 3,36 \\
Alemanha Oriental & 1,07 & 1,16 & 1,06 & 1,22 & 2,88 \\
Áustria & - & - & 1,45 & 1,87 & 3,38 \\
Bélgica & 1,11 & 1,41 & 1,46 & 1.51 & 3,74 \\
França & 1,41 & 1,64 & 1,90 & 1,95 & 2,81 \\
Grã-Brctanha & 0,50 & 0,56 & 0,59 & 0,61 & 1,50 \\
Suíça & 1,17 & 1,42 & 1,55 & 1,69 & $* 3,40$ \\
\hline
\end{tabular}

Fonte: BMG, 1997; Schncider et al., 1997. *1991.

\section{Médicos por especialidade}

O nível de especialização dos médicos credenciados vem aumentando de modo gradativo. Em 1970, mais da metade dos médicos (55\%) era de clínicos gerais; já cm 1990, esta proporção baixou para 42\%. O mesmo ocorre para pediatras, ginecologistas e internistas (contabilizados como especialistas, embora excrçam funções similares às de clínicos gerais), o que corrobora a tese da gradual especialização da atençāo ambulatorial.

A progressiva redução da proporção de clínicos gerais sugere a perda de atrativo cconômico destas atividades. A rigidez da tabela de honorários médicos foi fator de estímulo à especializaçāo. Em virtude de dificuldades de negociação entre médicos e Caixas, o processo de reajuste de preços da tabcla é moroso. As necessárias reduções periódicas de preços de serviços médicos técnicos em razão de amortização dos investimentos ${ }^{114} \mathrm{e}$ os forçosos reajustes das ações médicas clínicas diretas correspondentes à elevação dos preços do trabalho, assim como a compatibilização dos valores das diversas açōes entre si, não ocorrem na periodicidade necessária. Desse modo, ações que empregam equipamentos tornam-se sobrevalorizadas, passando a ser fator de estímulo à prestação de serviços médicos especializados e à incorporação de tecnologias para diagnóstico e terapêutica (Behaghel, 1994).

Como resultado desse processo, a longo prazo, as especialidades médicas na base da escala de rendimentos são aquelas cujas atividades estão constituídas especialmcnte por ações médicas pessoais, ou seja, exame físico e aconselhamento.

114 As importantes reduções nos preços de métodos diagnósticos por imagem, como ultra-sonografia e tomografia computadorizada, exemplificam esta situação. Novas ações técnicas são, em geral, incorporadas à tabela de honorários com preços altos, pois a primeira geração de cquipamentos é mais cara. Com o passar do tempo, o abatimento do investimento torna a prestação gradualmente menos oncrosa. 
Quadro 1 - Evolução do número de médicos credenciados e proporção de clínicos gerais, Alemanha Ocidental - 1970-1993. Alemanha - 1995

\begin{tabular}{|lcccc|}
\hline Ano & $\begin{array}{c}\text { Médicos de } \\
\text { Consultório }\end{array}$ & $\begin{array}{c}\text { Médicos } \\
\text { Credenciados }\end{array}$ & $\begin{array}{c}\text { \% Médicos } \\
\text { Credenciados }\end{array}$ & $\begin{array}{c}\text { \% Clínicos } \\
\text { Gerais }\end{array}$ \\
\hline Alemanha & Ocidental & & & \\
\hline 1970 & 48.830 & 46.302 & 95 & 55 \\
1975 & 52.913 & 49.928 & 94 & 50 \\
1980 & 59.777 & 56.138 & 94 & 44 \\
1985 & 67.363 & 63.694 & 95 & 43 \\
1990 & 75.521 & 71.711 & 95 & 42 \\
1991 & 77.547 & 74.063 & 96 & 41 \\
1992 & 80.520 & 77.276 & 96 & 41 \\
1993 & 88.844 & 85.769 & 97 & 39 \\
\hline Alemanha & & & & 40 \\
\hline 1995 & 110.949 & 107.497 & 97 & \\
\hline
\end{tabular}

Fonte: SVR, 1994; KBV, 1996. Cálculos próprios.

\section{Ações prestadas e casos tratados}

Tanto o volume de açōes prestadas como o número de tratamentos ambulatoriais por segurado vêm aumentando gradualmente. As estatísticas oficiais contabilizam as ações ambulatoriais na qualidade de casos. Um caso é o conjunto de contatos de um paciente com mesmo médico durante um trimestre. ${ }^{115}$ Como se pode observar na tabela 8 , enquanto o número de casos contabilizados por segurado foi de 4,8 em 1985, esta freqüência tinha alcançado 6,9 em 1995, correspondendo a um aumento de $44 \%$ no período.

Assim, embora o número de médicos credenciados tenha crescido de maneira expressiva e o número de segurados tenha permanecido constante, a quantidade de casos tratados por médico não diminuiu proporcionalmente, como seria de esperar. Oscilou entre 4.200 e 4.600 casos por médico ao ano, voltando a atingir, em 1995, o nível de 1980.

Parte desse aumento foi induzido pelos próprios médicos que passaram a contabilizar maior número de ações por caso, assim como solicitaram mais encaminhamentos e retornos. Ou seja, o crescimento dos casos contabilizados foi provocado não pela utilização primária, de iniciativa dos segurados (que sofre leve

11.5 Em outras palavras, um segurado pode consultar diferentes médicos no período, contabilizandose um caso para cada médico. 
declínio), mas em razão do acréscimo de solicitações dos próprios médicos. Estudo realizado para o conjunto das Caixas 'Primárias', 116 para a década de 1980 , mostra que o número de casos contabilizados no período elevou-se em 13\%, em decorrência de maior quantidade de encaminhamentos e retornos solicitados pelos médicos, enquanto a demanda ambulatorial primária declinou em 1,3\% (Klose, 1993).

Como o númcro de médicos aumentou no período, ocorreu, ao mesmo tempo, a redução do número de casos contabilizados anualmente por médico $(-12,2 \%)$. O número de pontos - unidades de serviços - contabilizados por médico, todavia, elcvou-se $\mathrm{cm} 18 \%$, o que resultou $\mathrm{cm}$ forte aumento do número de ações prestadas por segurado (50\%) e por caso tratado (55\%) (Klose, 1993).

Já a partir de 1993 houve intensificação da procura direta do segurado por especialistas em razão da implantação do cartão magnético do segurado.

\section{Tabela 8 - Produção ambulatorial do GKV. Alemanha Ocidental - 1980-1995}

\begin{tabular}{lccccc}
\hline Ano & $\begin{array}{c}\text { Casos em } \\
\text { milhares }\end{array}$ & $\begin{array}{c}\text { Casos/ } \\
\text { Segurado }\end{array}$ & $\begin{array}{c}\text { Casos/ } \\
\text { Contrib. }\end{array}$ & $\begin{array}{c}\text { Casos/ } \\
\text { Médico }\end{array}$ & \$DM/Caso* \\
\hline 1980 & 252.069 & - & 7,1 & 4.522 & 57,59 \\
1985 & 268.347 & 4,8 & 7,4 & 4.256 & 69,89 \\
1990 & 320.828 & 5,8 & 8,5 & 4.505 & 76,01 \\
$1995^{* *}$ & 400.760 & 6,9 & 9,9 & 4.546 & - \\
\hline
\end{tabular}

* Valor em marcos alcmães a preços correntes; **Inclui Berlim Oriental.

Fonte: KBV, 1996. Cálculos próprios.

O aumento gradual do número de casos tratados por habitante/ano na Alemanha segue o padrão de outros países. O número de contatos médicos por habitante/ano tem aumentado de modo gradual entre os países da OECD (1997). Durante os anos de $1990,{ }^{117}$ a tendência ao aumento da concentração de consultas médicas permanece, embora a evolução seja mais lenta do que nos anos de $1980 .^{118}$

Não é fácil avaliar a freqüência de contatos médicos realizados pelos segurados do GKV em comparação com outros países por causa da relação entre a contabilização dos contatos c a forma de remuneração. Ou sâo contabilizadas as

116 Denominação utilizada para referência às Caixas criadas por Bismark atravês da RVO Reichsversichcrungsordnung, ou seja, não inclui as Caixas Substitutas.

117 Em razão da disponibilidade de dados, esta observação concerne à primeira metade dos anos 90 .

118 Entre os 17 países para os quais são apresentados dados para os anos 90, observa-se leve aumento no número de contatos médicos per capila em 12 países; nos outros, esta relação se mantém quase estável ou se nota pequena redução na concentraçāo de consultas durante a primeira metade dos anos 90 . 
unidades de serviço e, então, o número de ações ambulatoriais é muito mais elevado, ou sāo contabilizados os casos, o que reduz a concentração, mas não expressa o número real de consultas médicas por segurado.

Segundo dados da OECD, o número de contatos médicos per capita na Alemanha é alto. Entre os 24 países da $\mathrm{OECD},{ }^{119}$ apenas Japão, Itália e Suíça apresentariam freqüência de consultas por habitante aproximadamente tão clevada quanto a Alemanha (tabela 9).

A concentração de consultas na maioria dos países da OECD é, em geral, elevada. Nos anos 90, em mais da metade dos países da OECD, a média de contatos mćdicos por habitante/ano estava acima de cinco e em vários deles acima de dez consultas/ano. Esta é a situaçāo da Alemanha, contudo, se forem considerados para a Alemanha os casos contabilizados - média de seis casos tratados por segurado/ano - aproxima-se do padrão da maioria dos países da OECD.

\section{Tabela 9 - Contatos médicos per capita ${ }^{120}$}

\begin{tabular}{lrrrrr}
\hline País & 1975 & 1980 & 1985 & 1990 & 1994 \\
\hline Japāo & 14,9 & 14,4 & 13,6 & 15,2 & 16,3 \\
Itália & 7,0 & 8,0 & 10,1 & $* 11,0$ & - \\
Alemanha Ocidental & 10,9 & 11,5 & 11,5 & $* 12,9$ & $* * 12,8$ \\
França & 4,8 & 5,4 & 6,7 & - & 6,3 \\
Sućcia ${ }^{121}$ & 2,6 & 2,6 & 2,7 & 2,8 & 3,0 \\
Grā Bretanha & 4,5 & 5,1 & 5,0 & 5,8 & - \\
EUA & 5,1 & 4,8 & 5,2 & 5,5 & 6,0 \\
\hline
\end{tabular}

*1988; **1992.

Fonte: OECD, 1993a; Schneider ct al., 1994; OECD, 1997; Schncider et al., 1997.

Na Alemanha, a expansão da produçâo ambulatorial acompanha o crescimento da oferta e está condicionada pelo modo de organizaçāo setorial e por incentivos dos mecanismos de regulação, em cspecial, do sistema de pagamento. Decorre principalmente de utilização secundária demandada pelo médico prestador e menos por iniciativa do próprio paciente. Na análise dos anos de 1980, esta influência, como descrito acima, fica evidente, pois, enquanto a utiliza-

119 Até 1994 faziam parte da Organisation for Economic Co-operation and Development (OECD) 24 países.

120 Estes dados são apenas ilustrativos. Observaram-se diferenças de informação nas diversas fontes consultadas.

121 Diferenças na cobertura de cotısultas estão condicionadas pela organização do sistema de atenção. Na Suécia, grande parte da atenção ambulatorial geral é prestada por meio de centros de saúde, e as enfermeiras têm maior compctência, realizando consultas de enfermagem de maior resolutividade. 
ção primária diminuiu levemente, o volume de ações produzidas por contato primário, em decorrência de iniciativa dos médicos, aumentou em 55\%.

$\mathrm{O}$ crescimento do volume de açóes prestadas por contato primário pode ser explicado por problema de distribuição. O menor número de casos em cada consultório induziria à maior contabilização de açōes pelo médico com o intuito de manutenção de sua remuneração, pois esta é determinada pelo volume de ações prestadas. A crescente concorrência levaria ainda a aumento dos investimentos $\mathrm{em}$ cada consultório, a fim de prestar serviços mais sofisticados. A multiplicação de ações scria necessária para cobertura destes custos, consequiência do cálculo econômico cmpresarial. A progressiva especialização médica também influenciaria a expansão do volume de ações prestadas. Com a especializaçāo, o espectro de serviços prestados se modifica, havendo intensificação dos custos e ampliação do número de pontos contabilizados por caso tratado.

Outros fatores têm provavelmente uma parcela de contribuição para a detcrminação da expansão do volume de ações. ${ }^{122}$ Contudo, esta análise deixa claro que o problema dos gastos crescentes, no caso da atençāo ambulatorial, foco das políticas de contenção, não decorreu de abuso dos segurados na utilizaçāo dos serviços de saúde, como querem fazer crer políticos conservadorcs. A constante expansāo da produçāo ambulatorial no período foi influcnciada pelos modos de remuneração e de alocação de recursos setoriais, que incentivaram os médicos prestadores a ampliar o volume de açōes prestadas por caso tratado e aumentar o número de encaminhamentos e retornos solicitados.

\section{Renda dos médicos}

Os médicos credenciados ocupam alto posto na escala de renda do conjunto dos profissionais liberais. Em 1995, a renda média bruta anual dos médicos credenciados - sem o desconto do imposto de renda - foi por volta de 200 mil marcos (cerca de US $\$ 130$ mil) na Região Ocidental. ${ }^{123}$ Em relação ao conjunto dos trabalhadores assalariados, a renda dos médicos era, em 1991, cerca de 3,7 vezes maior do que a renda média do trabalho assalariado. ${ }^{124}$ Para Alber (1992), a alta renda garantida aos médicos na Alemanha seria decorrente das vantagens estruturais que as Associações de Médicos das Caixas detêm no sistema de regulação do setor ambulatorial.

122 Outra explicação possível seria o aumento das exigências da demanda. O velho aforismo 'a oferta condiciona a demanda' nẫo se traduziu imediatamente $\mathrm{em}$ aumento da utilização primária, que não aconteccu, mas poderia ter resultado em demanda por aşós de maior valor em cada contato, por sua vez cstimulada pela propaganda (em senticlo lato, de todo o complexo médico industrial) de oferta mais sofisticada (Klose, 1993).

123. Relativa a faturamento médio de 370 mil marcos por consultório (em torno de US\$218 mil), $80 \%$ deste correspondente à prestação de serviços às Caixas.

124 Observa-se uma reduçĩo relativa da renda dos médicos desde os anos 70 . Em 1967, a renda dos médicos era de 6,7 vezes a do trabalho assalariado. 
Ainda que continuem em posiçāo vantajosa em relação a outros trabalhadores, o nível de renda dos médicos tem declinado. Com o aumento progressivo do número de médicos credenciados, observa-se leve redução da renda média dos médicos individualmente, em especial, desde o início dos anos $80 .{ }^{125}$

Diversos autores apontam como principal resultado das medidas de contenção sobre a corporação médica, a longo prazo, esta reduçăo na renda dos médicos, por conta de efeitos incrementais cumulativos, decorrentes das pequenas alterações proporcionadas pelas diversas leis (Bchaghel, 1994; Döhler \& ManowBorgwardt, 1992). Contudo, é difícil identificar tais alterações como relacionadas a uma intenção direta do legislador, pois a renda média individual dos médicos diminuiu também por conta do forte crescimento do número de médicos credenciados.

\section{Mecanismos de regulação}

A regulação da atenção ambulatorial processa-se de modo principal por intermédio de negociaçōes entre os atores sctoriais. A atenção ambulatorial é.o setor da atenção em que os arranjos corporativos característicos do sistema alemão, por meio dos quais o Estado delega a regulação de determinado setor da socicdade aos atores imediatamente envolvidos, são mais difundidos. As Associações de Médicos das Caixas (Kven), como forma de agregação dos prestadores de açōes ambulatoriais, exercem o papel principal. Negociam o volume e a remuneraçāo dos serviços a serem prestados com as Caixas provedoras do scguro social, garantem que seus afiliados - os médicos credenciados - prestarão os serviços conforme legislado e contratado, além de repartirem o total dos honorários, que lhes são pagos pelas Caixas, entre os médicos credenciados de acordo com os serviços prestados.

As Associações de Médicos das Caixas funcionam como monopólio na prestação da atenção ambulatorial ${ }^{126}$ e monopólio de representação dos médicos credenciados, garantindo-lhes posiçāo dominante na distribuição de poder ao interior do sistema de saúde. Esta posição de força se expressa tanto frente aos pacientes como ante às Caixas. Possibilita-lhes definir preço, quantidade e qualidade dos serviços prestados sem controles importantes e efetivos de outras instâncias (Wanek, 1994).

125 Entre 1976 e 1987, ocorreu reduçāo do nível real da renda média dos médicos, entre 4\% e $9 \%$, conforme o índice de deflação empregado.

126 As Associações de Médicos das Caixas foram criadas em 1931, mas o monopólio dos médicos de consultório na atenção ambulatorial tem origem na Alemanha nazista. Em 1933, logo nas primeiras semanas da ditadura nacional-socialista, a administração das Caixas foi cxpurgada de 'judeus c pessoas de ideologia diferente da nazista' (Andersdenkenden), e os lugares livres, ocupados por membros do partido nazista. Os serviços ambulatoriais próprios das Caixas, criados durante as greves médicas de 1923-24, foram imediatamente fechados. Em 1935, cerca de um terço dos médicos não judeus era filiado à Associação Nazista de Médicos. 
É vedado às Caixas prestarem serviços assistenciais e negociarem contratos com grupos de médicos. Este monopólio possibilita, aos médicos, alta capacidade de implementar seus interesses, em particular hoje, com a dispersão das Caixas em competição entre si por mais segurados (Stegmüller, 1996a).

Esta forma regulada de organização dos médicos credenciados, por sua vez, tem como vantagem a produção de forte coesão e capacidade de implementação dos acordos realizados entre a direção das associações de médicos e de Caixas, ao garantir compulsoriamente a adesão dos médicos e ao responsabilizar as Kven pela administração financeira setorial. As Associações de Médicos das Caixas têm forte ascensão sobre seus associados, o que facilita a negociação das Caixas com os médicos e garante a continuidade da atenção.

Se esta forma de organização, por um lado, pode ser caracterizada, de certo modo, como 'monopólio dos prestadores', ${ }^{127}$ por outro lado, dada a concorrência entre as Caixas, pode vir a significar garantia de atençāo mais uniforme ao conjunto dos segurados.

A posição dos médicos nas últimas décadas ter-se-ia enfraquecido. Ocorreu diminuição de renda e hierarquizaçāo ao interior da corporação, havendo maiores conflitos pela repartição dos honorários em virtude do controle dos gastos setoriais paralelamente ao aumento do número de médicos. Para Behaghel (1994), as mudanças da legislação nos últimos anos produziram dois efeitos principais sobre a corporação de médicos credenciados: o grau de liberdade de ação das Kven frente às Caixas foi gradualmente reduzido e foram alterados o espaço de ação e a estrutura dos estímulos a cada médico. O espaço de açāo do médico individual não foi alterado diretamente pela legislação. Sua reduçāo é decorrência de novos mecanismo de regulação sobre as Kven, que passaram a controlar mais fortemente as atividades de cada um dos médicos em razão da ameaça latente de coerção.

\section{Credenciamento}

Um dos mecanismos de regulação da atenção ambulatorial expressa-se no processo de credenciamento. Efetua-se o credenciamento dos médicos através de sua filiaçāo às Associações de Médicos das Caixas (Kassenärztliche Vereinigung Kven). Entre cada médico e as Caixas não há, portanto, contrato ou credenciamento individual. Essa relação é mediada pelas Associações de Médicos das Caixas.

A solicitação de credenciamento é feita pelo médico interessado à Associação de Médicos das Caixas da respectiva região e julgada por uma comissão de admissão constituída paritariamente por representantes das Caixas e da Associação. Além do credenciamento, outra possibilidade para participação na atenção

127 Note-se ser esta forma de organização da prestação ambulatorial fontemente regulada, muito distinta de monopólios econômicos em outros setores. 
ambulatorial das Caixas é a autorização. Médicos especialistas que trabalham em hospitais são autorizados a exercer atividades ambulatoriais para o GKV. Esta forma de participação ć pouco freqüente e é utilizada apenas para cobrir a falta de especialistas em determinada região.

Durante muito tempo, a possibilidade de credenciamento foi irrestrita. Os médicos eram credenciados quase que automaticamente depois de completarem a formaçāo. ${ }^{128} \mathrm{~A}$ falta de critério na admissão de médicos levou à ampliação pouco criteriosa da oferta e a sérias distorçōes quanto a sua distribuição espacial. Desde meados dos anos 70 , foram implementados procedimentos de condução da admissão de médicos, oscilando-se na intensidade dos controles estabelecidos.

Em 1976, as Associações de Médicos das Caixas (Kven) passaram a ser obrigadas a negociar planos estaduais de necessidade com as Caixas e criar estímulos ao estabelecimento de médicos em regiōes desassistidas, a fim de combater deficiências na assistência das populaçōes rurais e periféricas. A partir de 1980, implementaram-se mecanismos regionais de controle do número de credenciamentos. Em 1986, após rápido crescimento do número de médicos credenciados, nova legislaçāo admitiu a interdição do credenciamento para certos grupos de médicos em regiōes com 'sobreassistência'.

Essas regras possibilitaram alguma condução do credenciamento, mas não impediram a expansão da oferta. Legislação mais restrita passou a vigorar em meados de 1993, com a Lei de Estrutura da Saúde - GSG. A definição de excesso da oferta de médicos credenciados tornou-se mais estreita, ponderada em 10\% da densidade média nacional de médicos por habitante, estabelecendo-se este como o limite máximo para credenciamentos, para cada região e especialidade. Com a nova legislação, as comissões regionais de admissão passaram a ser obrigadas por lei a interromper as admissões no caso de oferta excessiva de médicos na especialidade em questão. ${ }^{129}$

\section{Sistema de remuneração e pagamento}

O valor c o preço das açõcs médicas são definidos mediante negociações de grupo entre as Associaçōes de Caixas e as Associaçōes de Médicos das Caixas em três níveis. A estrutura de preços é definida em nível federal, a partir de tabela nacional de valoração relativa das ações médicas, elaborada por Comissão conjun-

128 Nos anos 60 , os médicos passaram a ter garantia de credenciamento na regiăo e especialidade de sua preferência - via associação às Kven - se o desejassem (Wanek, 1994).

129 Esta nova legislação, porém, condicionou uma onda de credenciamentos em 1993. A GSG resuringiu o número de credenciamentos futuros, mas dcixou lacuna de meses para a entrada em vigor da restrição, o que produziu um boom de credenciamentos. O número de médicos credenciados elevou-se em cerca de $10 \%$ naquele ano, taxa igual à do conjunto dos quatro anos anteriores. 
ta composta pelas Associações Nacionais de Caixas e pela Federação Nacional de Médicos das Caixas (Kassenärztliche Bundesvereinigung - KBV). A remuneração global para a atenção ambulatorial é negociada com cada uma das Associações de Médicos das Caixas, em sua maioria de circunscriçāo estadual, com as Caixas. A distribuição dos honorários entre os médicos credenciados é efetuada segundo norma de distribuição, conforme o tipo e a quantidade dos serviços prestados pelas associações médicas regionais.

\section{- Valoração dos honorários}

Tabela federal única define o valor relativo das açōes ambulatoriais: norma única de valoraçāo Einheitliche Bewertungsmassstab - EBM. Nesta tabela são listadas mais de sete mil diferentes açōes médicas e laboratoriais - correspondentes a unidades de serviço - agrupadas em ações básicas e por especialidades, cujo valor é determinado em números de pontos (KBV, 1994). ${ }^{\text {:3o }}$

Por intermédio da norma única de valoração, discriminam-sc as ações passíveis de remuneração, bem como a estrutura de preços. A cada açāo é adscrito um valor em número de pontos, o qual decorre da comparação das açōes entre si. Os pontos correspondem à relação de valor entre as ações. A norma inclui ainda regras para contabilização de diferentes ações para o mesmo caso, isto é, a compatibilidade ou não de diferentes ações para sua remuneração.

A tabela é acordada em nível nacional e faz partc do contrato 'guardachuva' estabelecido para garantia da atenção ambulatorial. É formulada por uma comissão de valoração composta paritariamente pelas Associaçōes Nacionais de Caixas e pela Federação Nacional de Médicos das Caixas (KBV).

\section{- Preços}

Os preços são acordados em nível estadual. Em geral, Caixas e Kven negociam anualmente o volume da remuneração total para o setor ambulatorial em cada estado. A remuneração global pode ser calculada, scgundo a lei, com base em taxas fixas, unidades de serviços, taxas por caso ou per capita (SGB, 1993). O montante de recursos alocados pelas Caixas ao setor ambulatorial em cada estado é distribuído entre o conjunto dos médicos credenciados conforme o volume de açöes que cada um presta.

A negociação em nível estadual ocorre, em geral, entre a Associação de Médicos das Caixas e cada uma das Associações de Caixas em separado. Desse modo, a mesma ação prestada para segurados de diferentes Caixas pode ter preço distinto. A evolução do valor monctário de cada ponto tem sido influenciada pela

130 A norma única de valoração foi criada em 1977 com a primeira lei de contenção de gastos do GKV. Anteriormente havia uma tabela de ações e preços para cada tipo de Caixa em scparado. Nos dias de hoje, essa norma é composta pela BMA-Bewertungsmassstab Ärzte para o conjunto das Caixas, e pela E-GO-Ersatzkassengebührordnung, válida para as Caixas Substitutas. 
competiçāo existente entre Caixas Substitutas e Locais. As Associações de Médicos habitualmente procuravam negociar, $\mathrm{em}$ primeiro lugar, com as Caixas Substitutas, as quais, por usufruírem melhores condições financeiras, na expectativa de melhor atendimento para seus segurados, apresentavam maior disposiçāo a concessões, para então utilizar cstes resultados como norma das negociações subseqüentes. As Caixas Locais viam-se obrigadas a seguir os contratos das Substitutas, tentando assim não perder sua atratividade para os segurados que desfrutavam da liberdade de escolha da Caixa (segurados voluntários e empregados). ${ }^{131}$

Como os preços são usualmente negociados em nível estadual, observamse expressivas diferenças regionais. Historicamente, estas têm relaçāo com as distintas estruturas financeiras e de riscos dos segurados de cada Caixa, assim como com diferenças econômicas regionais, uma vez que as receitas de contribuição sāo dependentes da economia da região (Brenner, 1990).

A negociação prévia de volume global de gastos ambulatoriais faz com que os preços finais sejam definidos apenas após a sua prestação. Ou seja, o valor monetário de cada ponto dependerá da quantidade de ações prestadas pelo conjunto dos médicos daquele estado no período.

Os orçamentos acordados são repassados às associaçōes regionais de médicos credenciados. Assim como estas são responsáveis pela garantia da atenção ambulatorial, o são também pela distribuição dos recursos entre os médicos de acordo com o volume de açōes prestadas. A distribuição dos honorários é efetuada pclas Associações de Médicos das Caixas, segundo norma de distribuição - dada pelo sistema de pagamento -, que deve considcrar o tipo e o volume de açōes prestadas pelo médico. A partir de julho de 1997, como se verá adiante, a norma de distribuição estipula teto máximo de pontos que podem ser remunerados, em média, para cada caso tratado por um médico.

\section{- Sistema de pagamento}

O sistema de remuneração das açōes ambulatoriais encontra-se em processo de reformulação, tendo passado por importantes modificações em curto espaço de tempo. Até 1995, o sistema de remuneração era calcado, de modo exclusivo, em uma infinidade de unidades de serviço. ${ }^{132}$ A cada unidade de scrviço era atribuído um valor em número de pontos e cada médico recebia o correspondente ao volume das unidades contabilizadas.

131 As Caixas Substitutas negociavam preços $15 \%$ a $20 \%$ mais elevados, pressionando os preços para cima. Este tipo de concorrência entre as Caixas produziu inflação nos preços e não sua redução, como preconizam os defensores de maiores estímulos à competição.

132 Originalmente, o sistema de remuneração do setor ambulatorial era baseado em modelo de capitação. Durante os anos 60 , período de crescimento econômico e de estabilidade da situação financeira das Caixas, os médicos realizaram seu antigo interesse de serem remunerados por unidades de serviço. 
Nesse sistema, uma consulta médica é constituída por uma série de subações, como por exemplo: exame completo de sistema orgânico, aconselhamento, esclarecimento das medidas terapêuticas, reccita etc. Para cada uma dessas açōes ou subações é atribuído um valor fixo em número de pontos. O cálculo dos honorários que um médico receberá pelo trabalho realizado consiste na soma do volume total de pontos correspondentes às ações produzidas, multiplicado então pelo valor monetário de cada ponto, negociado regionalmentc pelas associações de médicos credenciados com as Caixas.

Nesta modalidade de pagamento por unidades de serviço, os médicos dispõem da possibilidade de elevar seus ganhos por meio da maximização da contabilizaçāo de ações (Deppe, 1987). De fato, o sistema de remuneração por unidades de scrviço, criado em 1965, gerou forte expansão dos gastos no setor ambulatorial e, em particular, da renda de cada médico até a introdução de políticas de contençāo na segunda metade dos anos 70 (Wanek, 1994). Desde 1977, por meio de negociação ou de definição legal de tetos orçamentários para o setor, acoplando-se a evolução dos gastos ao crescimento da renda dos segurados, o valor monetário de cada ponto passou a depender do maior ou menor volume de açōes prestadas pelo conjunto dos médicos. Isto é, o aumento do volume de serviços prestados leva à reduçāo do valor de cada ponto.

$O$ sistema de remuneração com base em unidades de serviço foi alterado na segunda metade dos anos de 1990. A valoração das ações segundo determinado número de pontos foi mantida, tendo-se introduzido, em 1996, o pagamento de complexos de ações e, a partir de julho de 1997, orçamentos por consultórios diferenciados conforme a especialidade, definidos com base no número de pacientes tratados em cada trimestre, bem como pela delimitação de volume máximo de ações per capita.

\section{Complexos de ações}

No início de 1996, o sistema de pagamento foi reformulado, passando a vigorar um sistema que prevê a inclusāo de pagamentos para determinados complexos de ações, associados à continuidade de unidades de serviços para as outras ações. O objetivo da reforma seria reduzir os estímulos à multiplicação de açōes, condicionados pelo sistema de remuneração. Ao mesmo tempo, tinha-se por objetivo a alteração do desequilíbrio existente entre a remuneração de ações com maior dispêndio de tempo - anamnese, exame físico e orientação - e de ações com emprego de tecnologia, a fim de alcançar balanço mais favorável às primeiras (Metzinger \& Woggon, 1997).

Nas últimas reformas da EBM têm sido criados incentivos financeiros à realização de procedimentos clínicos. A tendência das reformulações anteriores do sistema de remuneração ambulatorial consistira em negociação de preços mais 
elevados para utilização de novas tecnologias c exames diagnósticos, enquanto as açōes que demandavam maior utilização de tempo e contato direto com o paciente (exames clínicos e aconselhamento) tiveram seus preços relativamente diminuídos (Powell, apud Guia, 1996).

Isso provocou defasagem dos valores correspondentes aos procedimentos clínicos, o que se tentou contrabalançar nas duas últimas reformas da EBM, quando os valores $\mathrm{cm}$ número de pontos destas ações foram aumentados e os novos complexos de ações clínicas tiveram valoração relativa mais alta do que o conjunto das unidades de serviço que os compõem.

Expressiva parte das açōes passou a ser remunerada pelo novo sistema. Ações típicas de cada especialidade foram agrupadas em complexos de açōes específicos para cada especialidade ( Ordinationsgebühr), que podiam ser contabilizados apenas uma vez por trimestre para cada caso tratado. O complexo de ações podia ser contabilizado à medida que uma das açōes integrantes do complexo fosse prestada e independente de quais e em que quantidade as açōes do complexo fossem prestadas ao mesmo paciente em cada trimestre.

Além disso, para cada novo contato médico-paciente, uma taxa básica de consulta era paga. As ações considcradas não delegáveis nem racionalizáveis, como, por exemplo, uma visita domiciliar, assim como açōcs mais custosas, em especial, as com alto emprego de equipamentos, continuaram a ser pagas por unidades de serviço. Para a valoração de cada um dos complexos de açōes foi tomado em conta tanto o dispêndio de tempo como a utilização de equipamentos (Gerlinger, 1997).

A concordância com esta reforma do sistema de pagamento significou importante mudança na posição da Associação Federal de Médicos das Caixas (KBV) em relação à tradicional defesa do sistema de pagamento por unidades de serviço. O resultado imediato, porćm, ao contrário da pretendida contenção da quantidade das ações, foi uma explosão no volume de açōes contabilizadas. Nos primeiros meses de 1996, o volume das ações prestadas cresceu em média $30 \%$ a $40 \%$.

Para muitos médicos, o complexo de ações passou a ser considerado como remuneração básica de cada caso. Além dos complexos de ações (Ordinationsgebühr), açōes relativas a aconselhamento e exame físico também aumentaram consideravelmente, em particular as contabilizadas por profissionais das especialidades gerais. Pediatras e clínicos gerais foram os que mais ampliaram a contabilizaçāo do númcro de pontos (Gerlinger, 1997; Balast, 1996).

Devido à concomitância de tetos orçamentários fixos para o setor ambulatorial, o aumento do volume de ações contabilizadas levou, mais uma vez, à redução drástica do valor monetário remunerado por ponto prestado. Médicos que não participaram do afã contabilista, ou especialidades cujos custos fixos são altos sofreram diminuiçăo $\mathrm{em}$ seus proventos. A disputa alocativa ao interior da corporação médica - em particular, entre clínicos gerais e especialistas - intensificou-se. 


\section{Praxisbudgets}

Em julho de 1997, entrou em vigor novo mecanismo para a remuneração dos médicos credenciados. Orçamentos por consultório (Praxisbudget) passaram a ser definidos a partir do cálculo de teto máximo de pontos contabilizáveis em média por caso tratado por especialidade. ${ }^{133} \mathrm{O}$ novo sistema de remuneraçāo leva em conta os custos diferenciados por especialidade, o volume de casos atendidos por médico, qualificações especiais de cada médico e diferenças regionais. ${ }^{134}$

$\mathrm{Na}$ discussão da nova forma de remuneração, reiterou-se o objetivo de interromper a expansāo do volume de açōes prestadas. Pretendia-se a redução do volume total de pontos contabilizados, o que elevaria, em conseqüência, o valor monetário de cada ponto. Do ponto de vista dos médicos, visou a alcançar a estabilidade do valor monetário dos pontos correspondentes às unidades de serviço, que estavam $\mathrm{cm}$ queda progressiva desde a introdução de orçamentos fixos para o setor ambulatorial. A estabilização desse valor possibilitaria, a cada um dos médicos, a previsão de suas receitas, pois conheceriam de antemão os preços dos serviços que prestam (Bundesärztekammer \& KBV, 1997b).

A formulação do novo sistema pressupõc que as verbas atualmente disponíveis para o setor ambulatorial sāo suficientes para cobrir as necessidades de atenção e remunerar de modo adequado os serviços prestados, da mesma forma que se supõe aceitável a atual estrutura de custos da atenção ambulatorial.

Três premissas orientam a lógica do novo sistema. Pondera-se que todos os médicos, independente da especialidade, têm direito a rendas similares por trabalho de intensidade comparável. A segunda premissa é a de que quem trabalha mais deve reccber mais. Quer dizer, o faturamento de consultório permanece acoplado à quantidade de casos atendidos. E, por último, que a EBM - tabela de valores - deve permanecer como a forma de valoração das açōes (Metzinger \&Woggon, 1997).

Definiu-se valor médio em número de pontos por caso tratado nas diversas especialidades c em cada região. O orçamento trimestral de cada Praxis passou a ser calculado por meio da multiplicação da norma de pontos de cada caso pelo número de casos tratados no período. Este volume de pontos é o limite máximo que será remunerado. ${ }^{135}$

133 Embora a denominação do novo esquema de remuneração seja Praxishudgct, o que signilica 'orçamento por consulıório', no caso de consultórios com mais de um médico, o teto de pontos é calculado para cada um dos médicos. Além disso, sāo previstos adicionais de até $35 \%$ conforme o número de participantes por consultório, como forma de estimular a criação de consultórios coletivos, pois os custos fixos diminuem de modo considerável.

$134 \mathrm{O}$ novo esquema foi decidido pela Bewertungsausschuss em novembro de 1996 (Bundesïrztekammer \& KBV, 1996: B-2618), e incluído na $2^{3}$ Lei de Reordenação da Saúde de junho de 1997.

135 O esquema de cálculo dos orçamentos por consultório e particularidades do Praxisbudget são apresentados em Giovanella, 1998. 
O orçamento por consultório é, na verdade, o teto máximo em número de pontos que será remunerado em média para o conjunto dos casos tratados. A norma de pontos definida por caso năo é limite para cada caso tratado em particular; multiplicada pelo número de casos, esta define um volume global de pontos por consultório. Dentro desse teto, o médico tem liberdade de prestar as ações que julgar mais adcquadas; prestar maior quantidade de açōes para alguns casos, menor para outros. Caso o número de açōes prestadas - leia-se total de pontos - para o conjunto de seus pacientes seja inferior ao teto, o médico recebe menos. Se ultrapassar o teto máximo, não recebe o valor cxcedente correspondente.

Com o novo sistema, considera-se que os médicos seriam liberados da 'necessidade econômica' à contabilização excessiva de ações e que, ao mesmo tempo, seriam remunerados adequadamente para prestar ações compatíveis às necessidades médicas de seus pacientes. ${ }^{136}$

O mecanismo promove redistribuição de rendas entre as diversas especialidades médicas. $\mathrm{O}$ pressuposto embutido na lógica de cálculo do orçamento - o de renda idêntica para os médicos de qualquer especialidade - implica a redistribuição ao interior da corporaçāo, favorecendo os médicos que exercem atividades gerais (Hausarzt) ${ }^{137}$ Isso não significa, porém, remuneração homogênea para o conjunto dos médicos, pois esta varia conforme o número de casos tratados e permanecem diferenças regionais. ${ }^{138}$

Os orçamentos são calculados regionalmente - regiōes correspondentes à abrangência de atuação das Associações de Médicos das Caixas, em geral, estaduais. Em âmbito nacional, define-se apenas a proporção média de participação dos custos no faturamento dos consultórios por especialidade. Se, por um lado, esta definição regional passa a representar de modo adequado sua estrutura de atenção, por outro, cristaliza importantes desigualdades regionais; os médicos de diferentes regiōes dispõem de orçamentos expressivamente diferenciados para tratar pacientes com problemas de saúde similares (Balast, 1996).

No processo de discussão em busca de consenso e de aperfeiçoamento do esquema, problemas foram levantados $\mathrm{e}$ introduzida uma série de particularidades e exceçōes (Bundesärztekammer \& KBV, 1997).

Algumas açōes tidas como não passíveis de igual distribuição entre os médicos de cada especialidade ou que só podem ser prestadas por médicos com treinamento específico ao interior da mesma especialidade não foram

136 O novo sistema de honorários exige dos médicos posicionamento diferente: maiores ganhos dependerão de prestação o mais econômica possível de serviços médicos. Na decisão quanto à ação a realizar, o médico terá de levar em conta os custos (Ärzte Zeitungen, 1997).

137 O novo sistema de pagamentos acirrou os conflitos distributivos entre os médicos. Certas especialidades consideraram-se prejudicadas na definição do número de pontos por caso.

138 Estas diferenças pouco têm a ver com o estado de saúde das populaçöes regionais, estando mais relacionadas a diferenças na densidade da oferta e à efetividade dos controles da quantidade das açōcs prestadas realizados pelas Associaçōes de Médicos das Caixas em cada estado. 
incluídas ou o foram parcialmente no teto orçamentário de casos globais por consultório. Para a inclusão das açōes no novo esquema, foi criada uma classificação: modelo semáforo.

As ações correspondentes ao orçamento normal fazem parte de uma 'lista verde'. As ações integram o orçamento normal quando constituem ações-padrão da especialidade. A 'lista amarela' é constituída pelas ações que dependem de qualificação adicional, prestadas apenas pelos médicos da especialidade. Orçamentos adicionais específicos para as mesmas são definidos para cada médico. E, finalmente, fazem parte da 'lista vermelha' aquelas que sāo excluídas do orçamento: ações altamente especializadas e custo-intensivas; açōes inovadoras incentivadas (cirurgias ambulatoriais), remuneração básica para clínicos gerais.

O sucesso do esquema depende da inclusāo do maior número possível de ações. Reconhece-se que, quanto maior o número de exceções, maior a probabilidade de que o controle da expansāo visado não se realize. O volume de açôes incluído no novo csquema varia entre as diversas especialidades. Alcança $88 \%$ das açôes para oftalmologistas e apenas $45 \%$ das açōes para anestesistas, por excmplo. Mesmo com todas as exceções, estima-se que entre $70 \%$ e $80 \%$ das ações médicas estão incluídas no novo esquema. $\mathrm{O}$ que, na opiniāo da corporação médica, garantiria o controle da espiral ascendente de expansāo do volume de açōes prestadas (Bundesärztekammer \& KBV, 1997: B-691).

Além disso, a contabilizaçāo de pontos por caso é diferenciada entre atendimentos de segurados aposentados e de segurados ativos, sendo a dos primeiros expressivamente mais alta em razão da co-morbidade presente em idades mais avançadas. Outra distinção quanto à contabilização do número de pontos é feita ainda conforme o volume de pacientes atendidos por médico no período. Consultórios com baixo número de pacientes têm seu número de pontos aumentado $\mathrm{em}$ $10 \%$, ao passo que aqueles com maior número de casos atendidos por médico têm o número de pontos por caso reduzido em $10 \%$ a $20 \%$.

O escalonamento do número de pontos de acordo com o volume de pacientes atendidos visa a prevenir possível expansāo do número de casos contabilizados, seja por retornos ou encaminhamentos.

Outros riscos do novo modelo são o racionamento, por parte do médico, das ações prestadas por caso tratado, a contabilização privada de ações (pagamento por fora) e maior quantidade de encaminhamentos para internação hospitalar. ${ }^{139} \mathrm{O}$ esquema estimula o racionamento de ações prestadas a cada caso, porém, é limitada a possibilidade de racionamento. Se o volume de açōes prestadas (pontos) for menor do que a média definida por caso, a remuneraçāo também será. Assim, o esquema 'quanto menor o número de ações prestadas a cada pacientc, maior o valor remunerado por unidade de serviço', somente é válida dentro destes limites.

I39 Tal fato produziria transferência de gastos ambulatoriais para o setor hospitalar. 
Embora tenham sido previstos mecanismos de controle, é provável que o raciocínio econômico-inflacionista dos médicos tente impor-se, encontrando subterfúgios para a ampliaçāo do número de casos. Os mais cépticos prevêem uma ciranda de encaminhamentos (Metzinger \& Woggon, 1997). Não vigorando delimitação do orçamento global para o setor, os gastos ambulatoriais sofreriam nova expansão. Foi acordado que as Associações de Médicos das Caixas ficam obrigadas a adotar medidas adicionais de controle se o número de casos aumentar mais do que $5 \%$ em comparação a igual período do ano anterior.

A aceitação do novo sistema de pagamento pela Federação das Associações de Médicos das Caixas (KBV) resultou de negociação e foi acordada com base na expectativa da definição prévia de preços: a delinição de valor monetário fixo por ponto. A delimitação do volume de pontos que o novo esquema prevê seria pressuposto essencial ao retorno à negociação de valor monetário fixo por ponto. De fato, com as Leis de Reordenamento - NOG - de 1997, apesar da redefinição do sistema de pagamento, a corporação médica foi vitoriosa. Foram abolidos os tetos máximos orçamentários e a vigorar uma estimativa flexível do volume de gastos totais (Richtgrösse), cuja ultrapassagem, além de ser prenegociada, não foi seguida de sanções.

\section{Alocação de recursos para o setor ambulatorial}

O orçamento dos gastos ambulatoriais é controlado desde 1977. Tendo por base o orçamento do ano anterior, o atual não deve ultrapassar a taxa de evolução das reccitas de contribuição. ${ }^{140}$ Com a definição deste teto orçamentário, o valor de cada ponto pago varia conforme a quantidade de açōes prestadas pelo conjunto de médicos credenciados. Isto é, dado um orçamento fixo, quanto maior o número de pontos cxecutados (ações) pelo conjunto dos médicos em cada estado, menor será o valor de cada ponto. Este cálculo é realizado a cada três meses para os serviços prestados no período anterior, de modo que o médico, quando presta o serviço, nāo conhece o preço que será pago pelo mesmo.

As restrições orçamentárias para o setor ambulatorial, paralelas ao crescimento do númcro de médicos credenciados e à evolução desigual de honorários das diversas especialidades, produziram a intensificação dos conflitos alocativos ao interior das Associações de Médicos das Caixas, cm particular entre clínicos gerais e especialistas, corroendo a legitimidade dessas organizaçōes (Schwartz \& Busse, 1996).

Como o orçamento é limitado, mas a remuneração é proporcional ao número de ações prestadas, cada médico busca elevar individualmente a sua parcela de participação no orçamento por meio da prestação de maior número de serviços. Embora este comportamento seja racional para cada um dos indivíduos, coletiva-

140 Este princípio de política de gastos orientada pelas receitas tornou-se oficial em 1977, com a primeira lei de contenção de custos (Kostendämp/ungsgesetz), a qual marcou o fim da era de livre barganha entre prestadores e Caixas. 
mente seria mais racional limitar o número de açōes e, desse modo, aumentar o preço individual de cada uma delas (dilema do prisionciro).

As Associações Estaduais de Médicos Credenciados, como instituiçōes corporativas, tentam proceder como agentes de racionalidade coletiva ao controlar aumentos excessivos da quantidade de açōes produzidas por médico em comparação com a média das ações prestadas por médico da mesma especialidade (Schwartz \& Busse, 1996).

Desde a metade dos anos 70 , diversas medidas para controle de gastos foram implementadas. Três períodos distintos podem ser caracterizados: 19761988 - controle de gastos voluntariamente negociado; 1989-1992 - determinação legal de negociação de orçamentos para o controle de gastos; 1993-1995 - definição legal do orçamento (Schwartz \& Busse, 1996).

Em 1976, pela primeira vez a Associaçāo Federal de Médicos das Caixas e as Associaçōes das Caixas acordaram percentuais máximos para aumento dos gastos do setor ambulatorial correspondentes à evoluçāo do conjunto dos salários de contribuição (Grundlohnsumme). Ou scja, a taxa de aumento anual dos gastos do setor ambulatorial não poderia ultrapassar a das receitas de contribuição, desconsiderando-se clevações das taxas de contribuição.

No período entrc 1976 e 1988, negociações voluntárias entre médicos e Caixas com o estabelecimento de acordos anuais possibilitaram controle das taxas de crescimento dos gastos ambulatoriais, tendo estas sido mantidas próximas à evolução das receitas de contribuição (Schwartz \& Busse,1996).

A atuação flexível das Associaçōes de Médicos das Caixas, contribuindo para a contenção de gastos no setor, é considerada como tendo por objetivo evitar intervençōes mais drásticas do legislativo e garantir sua posiçāo privilegiada na constelação de poder setorial (Lauer-Kirschbaum, 1994). Esta estratégia de atuação teve como resultado uma evolução dos gastos do setor ambulatorial, em geral mais moderada do que em outros setores.

Em 1989, a estratégia de sucesso do passado tornou-se obrigação legal com a Lei da Reforma da Saúde (GRG). As Associaçōes de Mćdicos das Caixas e as Caixas foram obrigadas a negociar teto máximo para o orçamento do setor ambulatorial, de modo a garantir a estabilização das taxas de contribuição. De fato, o orçamento foi legalmente predeterminado.

O espaço de liberdade deixado foi apenas em relaçāo a algumas ações tidas como inovadoras e a açōes preventivas, para as quais foram abertas exceções quanto à possibilidade de aumento. As Associações de Médicos e as Caixas utilizaram tão bem essas lacunas que os orçamentos cresceram mais do que as receitas de contribuição (Schwartz \& Busse, 1996). ${ }^{143}$ A introdução da negocia-

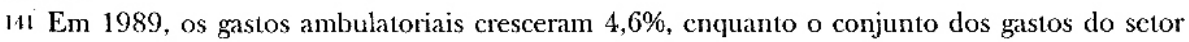
diminuiu $3,3 \%$, diferença de 7,9 pontos em termos percentuais. 
ção obrigatória dos orçamentos não teve, portanto, tanto sucesso como o processo anterior de acordos voluntários.

Em 1992, com a Lei da Estrutura de Saúde (GSG) -, os orçamentos estaduais para o setor ambulatorial passaram a ser definidos legalmente por um período de três anos (1993-1995). Sua taxa de crescimento foi fixada, passando a ser a mesma da taxa de aumento do conjunto dos salários de contribuição, e sanções financeiras no caso de sua ultrapassagem foram definidas.

Esta medida produziu desaceleração dos gastos da atenção ambulatorial. Suas taxas de crescimento em 1993 e 1994 foram mais baixas do que nos anos anteriores. O impacto, porém, foi bcm menor do que em outros setores. Em 1993, enquanto os gastos do GKV, como um todo, diminuíram, os gastos do setor ambulatorial continuaram a aumentar. Em 1995, os gastos do setor ambulatorial voltaram a subir a taxas similares às anteriores, esvanecendo-se os efeitos das últimas medidas de contenção. Em 1996, evoluíram mais rapidamente do que as reccitas de contribuiçāo.

Em 1997, contudo, a legislação da terceira etapa da reforma, em contrapartida à definição de novo sistema de pagamento, extinguiu os tetos orçamentários ambulatoriais e foi reaberta a possibilidade de definição prévia do valor monetário de cada ponto. Os tetos fixos e as sanções correspondentes foram substituídos por volumes orçamentários orientadores. Com a posse da nova coalizão governamental em 1998, a social-democrática/verdes, novos tetos orçamentários foram definidos legalmente.

\section{Mecanismos para controle da eficiência}

A remuneração dos médicos com base $\mathrm{cm}$ unidades de serviço sob a condição de limitaçāo de teto para o volume global de honorários faz com que as Kven procurem controlar a extensão do volume de açōes prestadas. Para tanto, foram estabelecidas formas de monitoramento econômico.

Provas de economicidade (Wirtschaftlichkeitsprüfungen) são realizadas por comissão constituída por representantes dos médicos e Caixas. Estas comissões examinam se o volume de serviços prestados por um médico situa-se em margem tolerável de desvio da média do conjunto dos médicos para aquela especialidade e, da mesma forma, se o volume de prescriçōes (medicamentos e outros métodos tcrapêticos), encaminhamentos para internação e atestados de dispensa para o trabalho mantêm-se dentro dos limites recomendados anualmente (SGB, 1993).

Desde 1989, a partir da Lei da Reforma da Saúde, são também efetuadas provas mais detalhadas (Stichprobcn) de amostra composta por $2 \%$ dos médicos a cada trimestre. Caso o volume de açōes prestadas ultrapasse certa proporção da 
média, estão previstas sançōes. O aconselhamento tem precedência sobre as sanções. Apenas em casos cxtremos (desvios maiores que $50 \%$ da média), os honorários são reduzidos ou restituições são exigidas (Alber, 1992).

Estas provas fiscalizam abusos individuais - desvios da média em relação à quantidade de serviços prestados -, mas não aferem ineficiência no comportamento do conjunto dos médicos. Não existe uma norma de eficiência previamente definida. A norma de comparação nessas provas é a média da prestação de serviços pelo conjunto dos médicos para aquela especialidade. Ao analisar apenas os desvios para mais em relação à média, estas provas são inadequadas para diagnosticar e/ou controlar comportamento pouco parcimonioso coletivo dos médicos de determinada especialidade.

Além disso, estas provas não contribuem para o controle da qualidade das ações prestadas. Um dos problemas da atenção ambulatorial é a insuficiência de mecanismos de controle de qualidade existentes. As Caixas, em geral, têm pouca possibilidade de verificação da qualidade da atenção ambulatorial prestada. Os médicos definem as necessidades dos pacientes e têm quase completa autonomia na decisão de quais ações são adequadas e nccessárias para a atenção de cada segurado (Wanek, 1994). O exercício predominante da prática ambulatorial em consultórios individuais não propicia trocas entre pares, ${ }^{1+2}$ mecanismo indireto de melhoria e controle da qualidade da atenção prestada.

Essas provas têm sido realizadas com maior ou menor ênfase nos diversos estados, o que tem produzido disparidades na prestação, evidenciadas pela comparação do número médio de unidades de serviço contabilizadas por caso. Em virtude dessas atividades de controle, as Associações de Médicos das Caixas são vistas, muitas vezes, pelos médicos, não como representantes de seus interesses, mas como órgãos de controle de sua remuneração. ${ }^{143}$

\section{Atenção Hospitalar}

Na Alcmanha, a atenção hospitalar é de responsabilidade pública da competência estadual. Os estados são responsáveis pelo plancjamento hospitalar, cabendo-lhes a definição da nccessidade de leitos e os investimentos hospitalares.

1.12 Como aquelas praticadas em hospitais: discussão de casos clínicos, formação de grupos de estudo, solicitação de parecer de outro profissional.

143 Para Alber (1992), a constituição das comissöes conjuntas de controle na reforma de 1977 teria levado à perda de legitimidade das Associaçōcs de Mćdicos das Caixas frente a seus associados. Este estranhamento pode ser observado empiricamente pelo número crescente de sociedades médicas em oposiçāo a essas associaçōes. 
Em regra, nāo é possível o accsso direto ao hospital; isto só ocorre nos casos de emergência e para pacientes particulares. Para a admissão hospitalar, fazse necessário o cncaminhamento de médico credenciado, facultando-se ao paciente a escolha do hospital, mas não do médico que o atenderá. ${ }^{144}$

Nos hospitais, os médicos são empregados assalariados e têm autonomia para definir a extensão e qualidade dos serviços prestados. Lugar importante na hierarquia médica é ocupado pelo médico-chefe de uma cnfermaria ou clínica. Este é responsável pela atenção de todos os pacientes do setor e depositário de total autonomia na definição dos métodos de tratamento, assim como detém uma séric de vantagens financeiras. ${ }^{1.5}$ A escolha dos pacientes das Caixas para tratamento pelo médico-chefe é possível como serviço opcional, desde que efetuem, em contrapartida, pagamento extra.

A quase totalidade dos hospitais existentes na Alemanha é contratada pelo conjunto das Caixas. ${ }^{146}$ Até bem pouco tempo, as Caixas eram obrigadas a contratar todos os hospitais incluídos no plano estadual. A partir de 1989, com a entrada em vigor da Lei da Reforma da Saúdc, as Caixas têm o direito de rescindir contratos com hospitais segundo determinados critérios, o que significa que podem incentivar a desativação de leitos.

O setor hospitalar é dos mais importantes ramos da economia, com gastos anuais totais de 96 bilhões de marcos (1994). ${ }^{1.17}$ Cerca de um milhão de pessoas estiveram empregadas no setor hospitalar (hospitais, casas de repouso e reabilitação - Kur) em 1994. Destas, cerca de 10\% eram médicos (Reister, 1996a).

Intensiva em custos e pessoal, a atenção hospitalar é o setor de atenção de participação mais elevada no total de gastos do GKV, sendo responsável, desde 1975 , por mais de $30 \%$ dos gastos. Dois terços das despesas no setor correspondem a gastos com pessoal, o que segue o padrão internacional. A necessidade de pessoal no setor hospitalar tem aumentado.

A dinâmica da elevação de gastos até a segunda metade dos anos de 1980 dependeu tanto do aumento do número de internaçōes como da ampliação da oferta de leitos e do aumento constante de preços, por conta da intensificação dos cuidados e de intervenções mais complexas, às quais estão relacionados procedimentos diagnósticos e de cuidados de custo mais clevado. Nos anos de

14 É comum que médicos encaminhem os pacientes ao hospital para esclarecimento diagnósti$c o$, pois temem perder o cliente se o referirem a especialistas credenciados, vistos como concorrentes (Alber, 1992).

145 Os médicos-cheles das enfermarias não são estritamente assalariados; tanto podem contabilizar no hospital de modo privado como exercer atividades em consultório próprio.

14 Apenas 79 hospitais, correspondendo a 2.793 leitos, não tinham contrato de prestação de serviços com as Caixas em 1994.

1.17 Cerca de 60 bithöes de dólares americanos. Nos tempos atuais, estima-se que trabalham no setor hospitalar mais pessoas do que na indústria automobilística (BMG, 1995a). 
1980 como um todo, os gastos hospitalares cresceram de modo mais lento, acompanhando o ritmo do crescimento dos gastos do GKV em geral. ${ }^{148}$ Durante os anos de 1990, voltaram a crescer.

Ainda que a corporação dos gastos hospitalares com saúde na Alemanha, se comparada com outros países, nāo seja alta devido à importância de sua participação no conjunto das despesas, estes gastos são responsabilizados pelos déficits financeiros do GLV e estariam na mira das tesouras. ${ }^{149}$ Argumenta-se que o setor hospitalar teria sido protegido da política de contenção de custos em decorrência da duplicidade de competências setoriais. $O$ financiamento da prestação é competência das Caixas, enquanto o financiamento de investimentos, planejamento $c$ regulamentação da atenção hospitalar são competência dos estados da federação. Assim, qualquer legislação sobre o setor, para vigorar, deve ser aprovada também pelo Conselho dos Estados (Bundesrat), que teria bloqueado medidas restritivas.

\section{Oferta hospitalar e produção de serviços}

Em 1994, existiam na Alemanha 2.337 hospitais com 618.200 leitos, representando uma relação de 7,6 leitos por 1.000 habitantes. Naquele ano foram produzidas 14,6 milhões de internações, o correspondente à taxa de internações anual de $18 \%$ da população. Os pacientes permaneceram internados, em média, 12,7 dias. A grande maioria dos leitos $(92,1 \%)$ situa-se em hospitais gerais e os restantes $7,9 \%$, correspondem a instalações hospitalares para tratamento psiquiátrico. ${ }^{1.50}$

$\mathrm{Na}$ Alemanha, além dos hospitais gerais e psiquiátricos, outras instituições atuam em regime de internação com o objetivo de prevençāo e/ou reabilitação. Em 1994 havia 1.329 instituiçōes para prevenção e reabilitaçāo $\mathrm{em}$ regime de internação (Kurhaus), com 173 mil leitos, tendo sido cuidados 1,7 milhōes de pacientes, que permaneceram internados 31 dias em média (StBA apud Reister, 1996b). ${ }^{151}$

148 Enquanto os gastos hospitalares cresceram $6,7 \%$ em média ao ano na década de 70 , esse índice foi de $1,4 \%$ entre 1980 e 1990 (OECD, 1995a).

14 Em cotejo realizado por Jelastopulu e Kaiser (1996) entre 20 países da OECD em 1990, esta proporção era mais baixa do que na Alemanha Ocidental $\mathrm{cm}$ apenas cinco países. Com proporção de $37 \%$, a Alemanha situava-se, por exemplo, abaixo da Grã-Bretanha (43\%) e da Itália $(49 \%)$, países com sistema de saúde organizado de forma hierárquica com porta de entrada na atcnção ambulatorial geral (capitação e gatekecper). Eun outro estudo, entre 22 países da OECD, a Alemanha Ocidental ocupava o $18^{2}$ lugar no ranking decrescente da proporção de gastos com internações (OECD, 1995:26).

150 O tempo médio de permanência nos hospitais psiquiátricos é de 52,3 dias, período maior do que a permanência nos hospiais gerais, que era de 11,9 dias em 1994 .

151 A descriçāo e a análise realizadas a seguir considerarāo apenas as instituiçōes classificadas como hospitais. Os serviços de internação para prevenção e reabilitação têm apresentado evolução diferente daquela dos hospitais. Encontram-se em expansão, 1endo crescido o número de instituiçōes, leitos e internaçōes ainda durante os anos 90 . O número de leitos destes serviços aumentou $20 \%$ entre 1991 e 1994 . 
O setor hospitalar na Alemanha tem se caracterizado por utilização crescente e declínio da capacidade instalada de leitos. Na primeira metade da década de 1990, o número de internaçōes e da proporção de pacientes internados no conjunto da população aumentou pouco a pouco, de forma concomitante à redução do númcro e da relação leitos/habitante em decorrência do processo de desativação de leitos. Observa-se ainda tendência ao encurtamento gradual do tempo médio de permanência e conseqüente reduçāo do volume total de dias de internação, aspectos que serão analisados a seguir.

Quadro 2 - Atenção hospitalar* Indicadores gerais. Alemanha - 19911994

\begin{tabular}{|l|r|r|r|r|r|}
\hline & 1991 & 1992 & 1993 & 1994 & $\Delta * *$ \\
\hline № Hospitais & 2.411 & 2.381 & 2.354 & 2.337 & $-3,1$ \\
№ Lcitos & 665.565 & 646.995 & 628.658 & 618.176 & $-7,1$ \\
Lcitos/10.000 hab. & 83,2 & 80,3 & 77,4 & 75,9 & $-8,8$ \\
№ Internaçōcs & 13.924 .907 & 14.233 .471 & 14.385 .416 & 14.626 .639 & $+5,0$ \\
Intem./100 hab. & 17,4 & 17,6 & 17,7 & 17,9 & $+3,2$ \\
Dias Intcrnação & 203.552 .000 & 198.028 .000 & 189.935 .000 & 185.178 .000 & $-9,0$ \\
T.M.P. & 14,6 & 13,9 & 13,2 & 12,7 & $-13,4$ \\
Taxa Ocup. & 83,8 & 83,6 & 82,8 & 82,1 & $-2,1$ \\
\hline
\end{tabular}

* Os dados referem-se ao conjunto de hospitais: gerais e especializados, inclusive hospitais psiquiátricos. **Variação 1994/1991.

Fonte: StBA, Wirtschaft und Statistik 6/1996:383.

Entre 1991 e 1994, concomitante ao aumento $\mathrm{cm} \mathrm{5 \%} \mathrm{do} \mathrm{número} \mathrm{de}$ internações, ocorreu clara redução do número e da densidade de leitos. Esta aparente contradição cntre aumento do número de internaçōes e desativação de leitos pode ser explicada pela notável redução $\mathrm{cm} 13 \%$ do tempo médio de permanência.

Enquanto os pacientes ficavam internados, em média, 14,6 dias em 1991, essa média correspondia a 12,6 dias em 1994. O incremento do número de internaçōes não foi suficiente para compensar os efeitos do encurtamento da permanência. Apesar desse aumento, o total de dias de internação diminuiu em $9 \%$ desde 1991, correspondendo a 185 milhōes de dias em 1994, o que provocou pequena redução das taxas de ocupaçāo paralelamente à desativação de leitos (Reiste, 1996a). 
As alteraçōes ocorridas neste período foram mais pronunciadas na região correspondente à ex-Alemanha Oriental, podendo-se observar uma aproximação ao padrão ocidental dos indicadores de atenção hospitalar da Região Oriental. Conquanto em 1991, ano da unificação alemã, o número de leitos por habitante e o tempo médio de permanência fossem mais altos na Região Oriental do que na Região Ocidental, esta situação inverte-se em 1994, ocasião em que os indicadores da Região Oriental passam a situar-se em patamares levemente abaixo dos indicadores da Região Ocidental.

\section{Leitos por tipo de prestador e porte do hospital}

Os leitos em hospitais gerais na Alemanha são predominantemente públicos. Em 1994, 57\% dos leitos existentes eram públicos e 37\%, filantrópicos. Apenas 5\% eram leitos privados. Entre 1991 e 1994 houve leve redução do número de leitos públicos e leve aumento dos leitos privados, porém, sem alterar expressivamente essas proporções (Reister, 1996a). ${ }^{152}$

Tabela 10 -Leitos em hospitais gerais e em instituições para reabilitação e prevenção em regime de internação, por tipo de prestador. Alemanha - 1995

\begin{tabular}{l|c|r|r|r}
\hline \multirow{2}{*}{ Prestadores } & \multicolumn{2}{|c|}{ Hospitais Gcrais } & \multicolumn{2}{c}{ Reabilitação e Prevenção } \\
\cline { 2 - 5 } & No & $\%$ & No & $\%$ \\
\hline Públicos & 319.999 & 56,7 & 30.115 & 16,6 \\
Filantrópicos & 212.459 & 37,6 & 26.999 & 14,9 \\
Privados & 32.166 & 5,6 & 124.527 & 68,6 \\
Total & 564.624 & 100,0 & 155.631 & 100,0 \\
\hline
\end{tabular}

Fonte: StBA, Wirtschaft und Statistik 6/1996; BMG, Datcn des Gesundheitswesens, Ausgabc, 1997:230-2.

Diferentemente dos hospitais gerais, os leitos em clínicas de reabilitação e prevenção em regime de internação (Kur) sāo, na sua maioria, privados $(65 \%)$. Apenas um quinto dos mesmos (19\%) são públicos e os restantes $15 \%$ são filantrópicos.

152 Essa redução de leitos públicos pode ser explicada pela maior desativação de leitos ocorrida nesse período na Região Oriental, onde os leitos eram todos públicos. 
A maioria dos leitos situa-se em hospitais de médio e grande porte. Cerca de $80 \%$ dos leitos gerais estão instalados nos 1.051 hospitais, com 200 leitos ou mais. Os hospitais privados são, em geral, de menor porte, com média de 84 leitos, bastante inferior à média de 273 leitos dos hospitais gerais públicos. Observa-se tendência ao aumento do número de leitos nos hospitais para agudos. Hospitais de maior porte são considerados mais cconômicos e, em alguns países, sua conformação tem sido estimulada. ${ }^{153}$

\section{Leitos por especialidade e por habitantes: desativação de leitos}

Mais da metade do conjunto de leitos hospitalares instalados em 1994 destinavam-se a internaçōes gerais de medicina interna e cirurgia (55\%), sendo 11\% específicos para atendimento psiquiátrico. Em 1991, a relação de leitos por habitante em geral e segundo a maioria das especialidades cra mais alta na regiāo oriental do que na ocidental. A situação inverte-se em 1994, em razão da desativação mais intensa de leitos na região leste.

Entre 1991 e 1994 foram desativados 47.385 leitos e fechados 74 hospitais na Alemanha. Cerca da metade dos leitos desativados (21 mil) eram leitos psiquiátricos, reduzidos $\mathrm{cm} 23 \%$ de seu total. Foram ainda desativados 10 mil leitos de medicina interna, 7 mil leitos destinados à ginccologia e obstetrícia e 5 mil leitos pediátricos, estes com a segunda maior redução proporcional (17\%).

A desativação de leitos, em geral, c de lcitos psiquiátricos, $\mathrm{cm}$ particular, foi muito mais intensa na ex-Alemanha Oriental, que reduziu à metade o número destes leitos. Ao contrário de 1991, a rclação número de leitos por habitantes em 1994 era menor na Rcgião Oriental para todas as especialidades, com exceção da pediatria.

A tendência à desativação de leitos para casos agudos e psiquiátricos não é recente. A capacidade instalada do setor hospitalar expandiu-se até a metade dos anos 70. A partir de então vem ocorrendo leve redução no número de leitos, tendência esta que se acentuou nos anos 90 . Desde 1977, o número de leitos em hospitais para agudos vem diminuindo, tendo alcançado em 1989 um patamar inferior a 1970 (Tabela 12).

Movimento similar aconteceu com o número de lcitos em hospitais exclusivos para tratamento psiquiátrico e/ou neurológico. Em contrapartida, o número de leitos em instalaçōes para reabilitação e para cuidados preventivos $\mathrm{em}$ regime de internaçāo hospitalar (Kur) continuou a crescer, ainda que $\mathrm{em}$ ritmo mais lento, durante os anos 80. Nos anos 90, a oferta de leitos nas casas de repouso para prevenção e/ou reabilitação expandiu-se de modo mais acentuado.

1.53 Em 1970, o número médio cra de 187 leitos por hospital, passando para 261 em 1989. 
Tabela 11 -Leitos hospitalares para casos agudos, psiquiátricos, e instalações para reabilitação e prevenção $(K u r)$. Alemanha Ocidental - 1960-1995 1.54

\begin{tabular}{cccc}
\hline Ano & Agudos & Psiquiátricos & Reab. e Prev \\
\hline 1960 & 399.839 & 95.922 & 32.059 \\
1965 & 422.199 & 105.299 & 51.062 \\
1970 & 457.004 & 116.862 & 60.244 \\
1975 & 489.756 & 118.241 & 86.276 \\
1980 & 476.652 & 110.833 & 91.045 \\
1985 & 462.124 & 96.578 & 91.520 \\
1989 & 452.283 & 89.396 & 102.961 \\
1995 & 441.312 & 58.892 & 157.942 \\
\hline
\end{tabular}

Fonte: BMG, 1993:259. BMG, 1997:232 e 240.

A desativação de leitos nos últimos anos na Alemanha acompanha tendência internacional. Esta redução do número de leitos, porém, ocorreu em ritmo mais lento do que em outros países. Entre 1980 e 1990, a rclação de leitos por habitantes em hospitais para tratamento de casos agudos na Alemanha Ocidental diminuiu em apenas $3,2 \%$. Proporçāo baixa se comparada com outros países como Dinamarca, Noruega e Suécia, onde esta redução alcançou cerca de $20 \%$ (Jelastopulu \& Arnold, 1994).

Mesmo com a desativação mais acentuada de leitos nos últimos anos, a Alemanha mantém a proporção mais elevada de leitos por habitante entre os países selecionados da OECD apresentados no Quadro 2. Alemanha, Luxemburgo, Áustria e Suíça são os países que mostram maior densidade de leitos para casos agudos, cntre 6 e 7 leitos por mil habitantes.

Todavia, se computado o conjunto dos leitos - agudos, psiquiátricos e de longa duração -, maior número de países apresenta relação leito/habitantes mais elevada do que na Alemanha. Suíça, Noruega, Holanda, Luxemburgo e Finlândia dispōem de dez leitos ou mais por habitante. Na Alemanha, considera-se que a quantidade de leitos disponíveis para cuidados de longa duração (nursing home beds) ${ }^{15 \tilde{5}}$ não é suficiente. Assim, paralelamente ao excesso de leitos para casos agudos, haveria escassez de leitos para pessoas dependentes de cuidados de longa duração (Alber, 1992).

15. A classificação por tipos de hospitais foi modificada ao implantar-se novo sistema de informações hospitalares a partir de 1990. A comparaşāo com a década de 90 fica parcialmente prejudicada, pois parte dos leitos pode ter sido reclassificada.

15.5 Não se emprega a denominação 'Tora de possibilidades terapêuticas', pois os leitos são destinados a pacientes, cm geral idosos, que necessitam cuidados de enfermagem, mas nāo necessariamente de tratamento médico. 
Quadro 3 - Leitos para casos agudos por mil habitantes; taxas de internação casos agudos por cem habitantes. Países selecionados - 1970-1995; Leitos totais - 1994

\begin{tabular}{|l|rrrr|r|rrrr|}
\hline & \multicolumn{7}{|c|}{ Lcitos casos agudos } & $\begin{array}{r}\text { Leitos } \\
\text { Total }\end{array}$ & \multicolumn{3}{|c|}{ Internaçōes casos agudos } \\
\hline Países & 1970 & 1980 & 1990 & 1995 & 1994 & 1970 & 1980 & 1990 & 1995 \\
\hline Alemanha** & 7,5 & 7,7 & 7,5 & 6,9 & 9,7 & 13,4 & 16,3 & 17,2 & $* 17,2$ \\
Áustria & - & - & 7,0 & 6,6 & 9,4 & - & 17,5 & 21,0 & 23,1 \\
Bélgica & 4,8 & 5,5 & 4,9 & $* 4,8$ & 7,6 & - & 13,9 & 16.9 & 18,8 \\
Canadá & - & 4,6 & 4,0 & $* 3,6$ & 5,4 & - & 14,6 & 12,0 & - \\
Dinamarca & - & 5,6 & 4,6 & $* 4,0$ & 5,0 & 14,3 & 17,6 & 20,6 & $* 19,7$ \\
Espanha & - & 4,4 & 3,4 & $* 3,2$ & 4,0 & - & - & 9,6 & $* 10,0$ \\
EUA & 3,9 & 4,2 & 3,6 & 3,3 & 4,2 & 14,3 & 15,9 & 12,5 & 11,7 \\
Finlândia & 4,8 & 4,9 & 4,3 & 4,0 & 10,0 & - & - & 16,3 & 20,0 \\
França & & 6,2 & 5,2 & 4,6 & 9,0 & - & 17,5 & 20,9 & 20,3 \\
Holanda & 5,5 & 5,2 & 4,3 & 3,9 & 11,3 & 9,7 & 11,2 & 10,3 & 10,3 \\
Itália & - & 7,6 & 6,1 & $* 5,3$ & 6,5 & 15,1 & 17,7 & 15,0 & $* 15,5$ \\
Noruega & - & 5,4 & 3,8 & 3,4 & 13,5 & 12,3 & 14,3 & 14,8 & 14,5 \\
Portugal & 4,3 & 4,1 & 3,6 & 3,4 & 4,3 & 6,7 & - & 10,6 & 11,1 \\
Reino Unido & - & 2,9 & 2,3 & 2,0 & 4,9 & - & 11,1 & 16,8 & 21,2 \\
Sućcia & - & 5,1 & 4,1 & 3,1 & 6,5 & 14,4 & 15,6 & 16,6 & 16,2 \\
Suíça & 7,1 & 7,1 & 6,5 & $* 6,1$ & $* 20,8$ & - & 13,0 & 13,9 & $* 14,3$ \\
\hline
\end{tabular}

*Dados de 1994; para Suíça, de 1993; **Dados da OECD, a partir de 1991, refercm-se à Alcmanha unificada, antes disso, apenas à Região Ocidental.

Fonte: OECD, 1997 Health data for Windows, Schneider et al., 1998:171 e 188.

A desativação de leitos nos países de industrializaçāo avançada tem sido uma das medidas empregadas para conter custos setoriais. ${ }^{156}$ Não é possível, porém, estimar objetivamente a necessidade real de leitos e há o perigo de se desativar mais leitos do que aqueles que seriam necessários à atenção. ${ }^{1.57}$ Além disso, paralelamente à suposta sobrecapacidade de leitos para casos agudos - em comparação com os EUA (3,3 leitos/mil habitantes) -, seria preciso que se instalassem mais leitos para alguns procedimentos e/ou condições específicas: geriátricos, centros

\footnotetext{
156 Na Itália, em 1995, as regiōes foram obrigadas por lei a desativar ou reestruturar hospitais com menos de 120 leitos (em asilos, em clínicas de reabilitação etc.). Na Bélgica, em 1986, foi disposto que um hospital deveria ter, no mínimo, 150 leitos e, até 1992 , mais de $30 \%$ dos hospitais tinham sido desativados ou transformados em asilos (Jelastopulu \& Kaiser, 1996).

157 Como é o caso de listas de espèra para cirurgias especializadas na Grã-Bretanha e para cirurgias eletivas na Dinamarca e Suécia (Jelastopulu \& Kaiser, 1996).
} 
de transplantes, de cirurgia cardíaca, clínicas para Aids. Novos leitos para cuidados de longa duração $\mathrm{cm}$ serviços específicos são ainda julgados necessários para evitar internações impróprias em hospitais para agudos - mais dispendiosos - de pessoas com perda de autonomia e dependentes de cuidados dc cnfermagem.

\section{Internações hospitalares: crescimento das taxas de internação}

Acompanhando tendência internacional, na Alemanha vem ocorrendo crescimento leve, porém gradual, das taxas de internação para casos agudos. Essa taxa situa-se entre as dez mais elevadas entre os países da OECD. ${ }^{158}$ Em 1994, o número de internaçôes por cem habitantes para a Alemanha como um todo alcançou 17,2\%. Na maioria dos países da OECD, assim como na Alemanha, houve crescimento das taxas de internação durante os anos 80 .

Já nos anos 90 , observa-se estabilização destas taxas ou leve redução em diversos países, ainda que persista a tendência à leve elevação em cerca da metade daqucles selecionados. Reino Unido e Áustria destacam-se por apresentarem crescimento expressivo nos últimos anos (Quadro 3).

Presume-se que exista conexão, nem sempre observada, entre a densidade de leitos e o volume de internações. Tradicionalmente considera-se que a oferta condiciona a demanda, o que significa dizer, neste caso, que a cxistência de número elevado de leitos na Alemanha é estímulo à maior produção de internações e/ou dias de internação. Isto é especialmente válido para Alemanha e Luxemburgo, mas não, por cxemplo, para o Reino Unido, que apresenta a mais baixa densidade de leitos agudos $(2,1)$, porém, é um dos campeōes na taxa de internaçōes por habitante (21\%) como se pode observar no Quadro 2.

$\mathrm{O}$ aumento das taxas de internaçāo, observado nos últimos anos $\mathrm{cm}$ diversos países, está relacionado principalmente a internaçōes de curı duraçāo e a reinternaçõcs de pacientes idosos. Na Alemanha, a proporção de internações entre pessoas idosas tem aumentado. Cerca de $50 \%$ do total de dias de internação são utilizados por maiores de 50 anos, embora este grupo corresponda a apenas cerca de $25 \%$ dos segurados (Alber, 1992). ${ }^{159}$

1.58 Taxas mais baixas de internação por luabitante em comparação internacional podem ser explicadas pela existência de maior articulação entre o setor hospitalar e ambulatorial. Ocorrem nos países em que os médicos de consultório acompanham seus pacientes nos hospitais e em países nos quais o tratamento especializado ambulatorial é realizado nos hospizais, como Holanda e Canadá (Jelastopulı \& Arnold, 1994). A existência de instalações especializadas em cuidados de longa duração contribui igualmente para taxas de internação mais baixas.

1590 tempo médio de permanĉncia aumenta com a idade; por isso, a participaçāo das pessoas mais idosas ć maior entre os dias de internação do que em relação ao número de internaçōes. 
Além disso, o número de internações de pcssoas que se dirigem primariamente ao hospital tem aumentado. Isto seria decorrência da escassez da oferta de atendimento de emergência ambulatorial, questão que tem sido objeto de discussāo e que promoveu a abertura de alguns serviços nos últimos anos.

Da mesma forma, o progressivo aumento do número de internaçôes por habitante é condicionado pelo modo de organizaçāo do sistema de atençāo - que carece de maior articulação entre os setores ambulatorial e hospitalar $-\mathrm{e}$ da forma de remuneração da atenção ambulatorial. A atençāo ambulatorial na Alemanha serviria de filtro à admissão hospitalar, uma vez que a internação só pode ser feita mediantc o encaminhamento por médico de ambulatório, exceto para casos de emergência.

A concorrência entre os médicos de ambulatório, todavia, estimula o encaminhamento dos pacientes a um hospital e não a um especialista, porque é certo o retorno do paciente ao médico geral após o tratamento hospitalar. Além disso, na situaçāo de remuneraçāo por unidades de serviços e de definição de teto máximo de gastos ambulatoriais, quanto maior o número de unidades de serviço prestado pelo conjunto dos médicos, mais baixo o valor de cada ponto. Assim, se o paciente necessitar de cuidado especializado, o médico prefere encaminhá-lo ao hospital, pois isto não influenciará sua remuneração.

Outro fator que contribui para o nível da taxa de internaçāo são as internaçōes desnecessárias. Na Alemanha, cstima-se que $20 \%$ das internaçōes hospitalares seriam evitáveis. Estudo recente do Serviço Médico das Caixas, efetuado em 40 hospitais, avaliou que até $24 \%$ dos casos internados em enfermarias de medicina interna poderiam ser tratados $\mathrm{em}$ ambulatório, caso houvesse instalaçōes adequadas, como consultórios especializados em determinadas doenças ou serviços para regime de internação parcial (MDS, 1997).

\section{Redução do tempo médio de permanência}

$\mathrm{Na}$ maioria dos países, assim como na Alemanha, a desativação de leitos é acompanhada por redução do número total de dias de internação, paralela à elevação das taxas de internação. Esta evolução é explicada, em parte, pelo concomitante encurtamento dos tempos médios de permanência (TMP). Isto é, tem sido cada vez menor o número de dias em que cada paciente permanece em tratamento sob regime de internação no hospital. Observa-se redução progressiva dos tempos médios de permanência $\mathrm{cm}$ todos os países da OECD desde os anos 70 (OECD, 1997).

Na Alemanha, o TMP tanto para os hospitais em geral como para os hospitais de agudos vem encurtando de maneira gradual. Entre 1990 e 1995, a permanência média nos hospitais para agudos na Alemanha foi reduzida em 2 dias, 
passando para 11,5. Esta evolução nos anos 90 é mais acentuada do que na década de 80 , quando a permanência média de 10 anos foi reduzida em apenas 1,5 dia. ${ }^{160}$

Embora tenha encurtado, o tempo médio de permanência na Alemanha é dos mais altos entre os países da OECD, representando o dobro dos tempos médios mais baixos que situam-se em torno de cinco a seis dias de internação. ${ }^{161}$ Todavia, a comparação internacional de TMP é complicada, pois a duração das internaçōes depende não apenas da morbidade e de diferentes estilos de tratamento prevalecentes em cada país, como também da divisāo de trabalho entre setor ambulatorial e hospitalar e da existência de adequadas instalaçōes para cuidados de longa duração. Desse modo, não se deve superestimar a potencialidade deste indicador para avaliar a eficiência da atenção hospitalar.

Embora preconizada como medida de contenção de gastos, a diminuição dos TMP, como discutido adiante, nāo leva à redução proporcional dos gastos hospitalares (Schwartz \& Busse, 1994). Para Jelastopulu \& Arnold (1994), a esperança de redução dos gastos hospitalares com a diminuição dos tempos médios de permanência seria infundada. Os custos ficam concentrados nos primeiros dias, quando há exigência de mais recursos e maior quantidade de pessoal para a prestação dos cuidados.

Paralelos à desativação de leitos e à diminuição dos tempos médios de permanência, observam-se ainda, no setor hospitalar, redução das taxas de ocupaçāo e aumento da rotatividade de leitos, acompanhando tendência internacional. A taxa de ocupação na Alemanha (81,3\% em 1995) é das mais altas entre os países da OECD. A rotatividade dos leitos na Alemanha vem aumentando, $\mathrm{cm}$ especial desde a segunda metade dos anos de 1980. Entre 1985 e 1995, o número de internaçōcs por leito aumentou 44\%, passando de 18 internaçōes ao ano para 26 em 1995.

\section{Mecanismos de regulação}

Em comparação ao setor ambulatorial, o hospitalar caracteriza-se por baixo grau de organização dos níveis intermediários de negociaçāo e fraca coordenaçāo e agregação dos interesses envolvidos.

Os prestadores hospitalares agrupam-se parcialmente em associaçōes, as sociedades de hospitais organizadas em nível cstadual e federal. Ao contrário da

160 $\hat{E}$ interessante observar que o tempo médio de permanência nos hospitais públicos é mais baixo do que entre os prestadores privados e filantrópicos. Isso provavelmente cstá relacionado ao sistema de pagamento segundo diárias uniformes, que estimularia os hospitais privados a deixar seus pacientes por mais tempo internados, garantindo maior receita.

161 Apenas Suíça e Holanda apresentam taxas tão elevadas quanto a da Alemanha. Reino Unido, Suécia, França Dinamarca apresentam as mais baixas taxas, em torno de 5 a 6 dias (OECD, 1997; Giovanella, 1998). 
Câmara Médica e Associações de Médicos das Caixas, estas são associações livres de caráter privado que não têm poder de diretiva sobre seus associados ou direitos assegurados pela via legal. Estas sociedades, em razão da diversidade de prestadores - públicos, privados, filantrópicos -, constituem-se separadamente, apresentando baixa capacidade de auto-regulação, de articulação e de imposição de seus interesses (Franke, 1989; Alber, 1992).

Esta baixa organizaçāo de interesses em nível intermediário na área hospitalar não implica entretanto em posição secundária da atenção hospitalar no sistema de atenção ou na disputa pelos recursos setoriais. Resulta principalmente em dificuldades de implementação dos consensos produzidos nesse nível, fazendo-se necessária a negociação das Caixas com cada um dos hospitais; o que restringe as possibilidades de mudanças setoriais.

Apesar de sua baixa capacidade de articulação de interesses, o setor hospitalar possui força oriunda de outras razões. Lma delas está na importância do hospital para a estrutura de atenção: encontra-se no final da cadeia do processo de atenção e é setor cuja defesa tem forte apelo moral, por evitar a morte de forma imediata e aliviar o sofrimento. Outra razão se refere à posição de importância do setor hospitalar na política regional, por ser responsabilidade dos estados a garantia da atençāo hospitalar e da competência estadual o seu planejamento.

Os principais atores no setor são os governos estaduais, responsáveis pelo planejamento das necessidades hospitalares, e os dirigentes hospitalares encarregados da negociaçāo de preços, que também se organizam, por sua vez, em associações.

As decisōes macrosetoriais exigem difícil processo de produção de consenso entre Uniāo e estados. O planejamento e a regulamentação da atenção hospitalar são competências exclusivas dos estados. Toda a legislaçāo referente à atenção hospitalar - garantia da atenção, planejamento e financiamento - deve ser aprovada obrigatoriamente pelo Conselho de Estados (Bundesrat).

\section{Planejamento hospitalar}

O planejamento hospitalar é incumbência dos estados. Mediante lei específica, em nível estadual, são definidos o tipo e o número necessário de hospitais e leitos. Desse modo, os estados orientam a qualidade e a quantidade da oferta. Não existem normas nacionais a serem seguidas para definição de necessidades. Os estados devern garantir também os meios financeiros necessários para os investimentos hospitalares, definidos nesse plano. A inclusão de um hospital no plano significa o seu credenciamento imediato pelas Caixas. ${ }^{162} \mathrm{~A}$ administração estadual define quais hospitais serão beneficiados por recursos públicos.

162 Para os hospitais não incluídos no plano estadual é necessário o estabelecimento de contrato especial com as Caixas. O número de hospitais com essa forma de contrato é pequeno. 
O planejamento hospitalar é indicativo e se implementa por meio de estímulos financeiros. Analisa-se a densidade de leitos por habitante e a necessidade de leitos é calculada com base no total de dias de internaçăo esperados, estimado a partir do número de casos e tempo médio de internação, e a taxa de ocupação de $85 \%$.

O primeiro passo na formulação do plano é a definição de quais hospitais preenchem as características de corresponder às necessidades médicas de atenção, ter capacidade de produção das ações necessárias e ser eficientes. No caso de avaliar-se positivamente maior número de hospitais/leitos do que a capacidade de leitos estimada como necessária, uma escolha 'segundo o interesse público' é feita pela repartiçāo competente. A diversidade de prestadores é preservada legalmente tanto para este tipo de decisão como para o caso de desativação de leitos.

Diversos atores setoriais participam do processo de planejamento hospitalar. Em geral existem Comissōes estaduais para o planejamento hospitalar, das quais participam, além da administração estadual, as Sociedades de Hospitais, as Caixas e representantes dos seguros privados.

Embora seja buscada a formação de consenso entre os diversos atores, o processo é considerado não muito transparente, e quem detém a última palavra na definição do plano é a administração estadual (Kolb, 1997).

O planejamento hospitalar estadual tem sido criticado pelas Caixas e pelo governo federal. Seria responsável por oferta desproporcional de leitos, o que, associado a estímulos do sistema de pagamento hospitalar, induziria a internações desnecessárias, provocando gastos excessivos.

\section{Financiamento da atenção hospitalap}

O financiamento hospitalar é de responsabilidade dos estados da Federação e das Caixas. Os investimentos são responsabilidade dos governos estaduais e compete às Caixas a manutenção hospitalar por meio do pagamento das internaçōes. Apenas os hospitais incluídos no plano - sejam estes estatais ou nāo - cstão aptos a pleitear e reccber investimentos públicos.

Desde 1984, os investimentos hospitalares sāo de responsabilidade exclusiva dos estados. ${ }^{163}$ Isso significou sobrecarga financeira para os orçamentos estaduais e, por vezes, a não realização de investimentos necessários (Franke, 1989). Esta forma de financiamento hospitalar compartilhada entre Caixas e estados tem sido denominada dual no debate recente sobre as reformas setoriais.

163 Por intermédio da lei de reordenamento hospitalar de 1984. Pela lei de financiamento hospitalar de 1972, os investimentos hospitalares haviam se tornado responsabilidade da União e dos estados, com participação dos municípios ou associações de municípios. A União deveria responsabilizar-se por um terço dos mesmos, o que não vinha acontecendo desde a metade dos anos 70, sendo esta participação abolida pela lei de 1984 . 
Tendo-se como pressuposto que a oferta induz à demanda, a desvantagem deste modelo seria que aquele a financiar os investimentos nāo teria responsabilidade quanto aos novos gastos induzidos. Os estados financiam ampliação da capacidade instalada - novos cquipamentos e leitos -, cuja utilização deve ser paga pelas Caixas. Vigem assim dois mecanismos autônomos, com diferentes perspectivas temporais: o plancjamento hospitalar com perspectiva de médio e longo prazo e a negociação de diárias com perspectiva de curto prazo.

A atual proposta $\mathrm{cm}$ discussão, em parte já legislada, é de que também os investimentos hospitalares passem a ser responsabilidade das Caixas. Esta mudança na legislação, ao mesmo tempo em que aliviará os orçamentos estaduais dos gastos com investimentos hospitalares, poderá enfraquecer a posição dos estados na política setorial. Sem competência no que se refere aos investimentos, os estados não disporão mais de importante mecanismo para direcionar a implementação do plano hospitalar sob sua responsabilidade. Esta mudança pode ser entendida também como 'desresponsabilização' governamental no que diz respeito à atenção hospitalar.

\section{Sistema de pagamento}

O sistema de pagamento do setor hospitalar foi recentemente reformulado. A remuneraçāo das internaçōes hospitalares pelo GKV tradicionalmente era feita mediantc o cálculo de taxas diárias globais de cuidado por hospital, que incluíam todos os gastos com pessoal, tratamento, manutenção e administração hospitalar. A partir de 1992, foram introduzidos pagamentos prospectivos diagnósticos relacionados para parte das internações, vigorando o sistema misto de pagamentos por diárias diferenciadas por enfermaria e diagnóstico relacionados.

Os orçamentos e preços das diárias de cada hospital são negociados ${ }^{164}$ anualmente entre as Caixas, por intermédio de suas associações, e cada um dos hospitais, independente de sua propriedade ser estatal ou privada. ${ }^{165} \mathrm{Em}$ geral, comissões de negociação são formadas pelos hospitais e Caixas em nível local, que negociam os preços para cada um dos hospitais em reuniōes conjuntas. Pelo lado das Caixas, é comum a Caixa Local tomar a frente das negociações. ${ }^{166}$

A Sociedade Estadual de Hospitais e a Associação Estadual de Seguros Privados também podem tomar parte nas negociaçōes. O objeto de negociação é o orçamento de cada hospital, elaborado com base no número de dias de internação

164 Até 1984, o valor monetário das diárias de cada hospital era definido pelas Secretarias Estaduais de Saúde. A partir de então, a hierarquia foi substituída pela negociação.

16.5 Note-se não ser fácil esta tarefa, pois as receitas hospitalares provêm das inúmeras Caixas do seguro social e dos seguros privados.

166 Agradeço a Thomas Kolb (1997), assessor da Associação de Hospitais de Hessen pelos esclarecimentos a respeito da dinâmica setorial. 
do ano anterior. Desde a Lei da Reforma da Saúde de 1988 (GRG), os preços acordados devem passar pela concordância tanto da Secretaria Estadual de Saúde quanto das Associações Estaduais de Caixas e dos Seguros Privados, o que teria alterado a correlação de forças em favor das Caixas (Alber, 1992).

O processo de negociaçāo de preços, assim como o sistema de pagamento, são definidos em nível federal por meio do decreto federal sobre as taxas de cuidados (Bundespflegesatzverordnung). Segundo as normas, para a negociação de orçamentos e diárias 'justas', adequadas às açôes médicas, devem ser realizadas comparaçōes entre hospitais com estrutura de atenção equivalente.

A organização de cotejo entre hospitais é encargo, em âmbito nacional, da Socicdade Alemã de Hospitais e das Associaçōes de Caixas. As Caixas deverão elaborar um catálogo comparativo de hospitais. Cabe aos estados dar suporte à negociação dos orçamentos e das taxas de cuidados; o governo estadual tem, como responsabilidade, a criação de comissão estadual e/ou regionais, composta paritariamente por representantes dos hospitais e Caixas.

\section{- Diárias uniformes}

Até recentemente, os custos de manutenção de um hospital deviam ser cobertos pelos serviços prestados por meio das taxas de cuidado - diárias - pagas pelas Caixas. Com isso, na negociação anual do valor das diárias de cada hospital, o cálculo das diárias partia da análise dos custos hospitalares totais do ano anterior, da estimativa de alguma taxa de evoluçāo para os mesmos e sua divisão pelo número de dias de internação previstos.

Calculava-se diária média única por hospital, a ser paga para qualquer paciente internado, independente da afecção a ser tratada, procedimento a ser cfetuado ou clínica responsável pela internação. Isso resultava em um número de valores de diárias aproximadamente igual ao número de hospitais contratados (Werner \& Seidel, 1996).

As taxas de cuidados cobriam complctamente os custos e eram reajustadas sempre que preciso. Orçamentos passaram a ser predefinidos apenas a partir de lei de contenção para o setor hospitalar em 1984. Os custos passaram a ser calculados com antecedência, com o objetivo de que os gastos nāo previstos fossem assumidos pelos próprios hospitais e introduzidas restriçōes na composiçāo de custos para os cálculos das taxas de internação.

O sistema de pagamento da atenção hospitalar mediante diárias uniformes diferenciadas por hospital sofreu intensas críticas. Se, por um lado, este sistema é de fácil administração e não representa estímulo à ampliaçāo de unidades de serviço, por outro, estimula o aumento da permanência.

O pagamento de diárias uniformes seria estímulo irrecusável para prolongar a permanência hospitalar, uma vez que cada um dos dias de internação 
é remunerado da mesma forma. Induziria os hospitais a compensarem os altos custos dos primeiros dias de internação com número correspondente de dias de custos mais baixos ao final do tratamento (Alber, 1992).

- Dagamentos prospectivos relacionados a diagnósticos e procedimentos

A partir de 1993, com a Lei da Estrutura de Saúde, foi abolido o princípio segundo o qual as taxas de internação deveriam cobrir os custos hospitalares. Diversificaram-se o sistema de pagamento hospitalar e as formas de remuneração. As remunerações deveriam passar a estar mais diretamente relacionadas às ações médicas realizadas (Tuschen \& Walzik, 1994). Implementou-se remuneração relativa à parte dos procedimentos realizados - sistema de pagamento prospectivo diagnóstico relacionado - e definiu-se a transferência gradual da responsabilidade dos investimentos hospitalares dos governos estaduais para as Caixas.

Adotoll-se um sistema de pagamento misto: pagamentos por procedimentos e diárias diferenciadas por tipo de clínica/enfermaria. Uma parte das internações hospitalares passou a ser remunerada mediante taxa por caso tratado relacionada ao diagnóstico, ou por meio de taxa especial concernente ao procedimento (pagamentos especiais).

Os pagamentos diagnósticos relacionados remuneram o conjunto de açōes realizadas para tratar um caso de internação hospitalar. Similar ao pagamento por procedimentos empregado no Brasil, tem por base os DRG-Diagnostic Related Groups norte-americanos. As remunerações especiais, por sua vez, referem-se apenas aos custos de determinados complexos de açōes, em especial cirurgias, aos quais é vinculado o pagamento de $80 \%$ da diária por enfermaria.

Em primeira etapa foram estabelecidos 40 pagamentos globais por caso (Fallpauschalen), relativos a 26 enfermidades e 104 remuneraçōes especiais (Sonderentgelte), e introduzidas diárias diferenciadas. Para internações nāo incluídas nos pagamentos por procedimentos e remuneraçōes especiais são negociadas diárias diferenciadas por enfermaria/clínica e uma diária básica para todo o hospital. A diária básica cobre os custos não diretamente médicos, inclusive hotelaria, e a diária especializada cobre o custo da atenção médica e de enfcrmagem.

A lista de procedimentos e remunerações especiais, assim como sua valoração $\mathrm{cm}$ números de pontos, similar à atenção ambulatorial, é definida em nível federal. O valor de cada um dos pontos é negociado $\mathrm{cm}$ nível estadual. Os preços pagos são, portanto, diferenciados conforme o cstado em que ocorre a prestação.

O novo sistema de pagamentos buscou redirecionar os estímulos financeiros, objetivando conter gastos. Os tempos médios de permanência normatizados 
para os pagamentos relacionados a diagnóstico têm por base médias históricas e cobrem os tempos de permanência observados. ${ }^{167}$

Em relação ao faturamento, a introdução de pagamentos diagnóstico-relacionados significou perda para os hospitais com diárias mais altas. Os valores pagos aos procedimentos foram calculados com base nas médias do conjunto dos hospitais, de modo que a contabilização de gastos de internação pelo novo sistema significará pequena vantagem para os hospitais de atenção geral básica e perdas para os de nível terciário, cujas diárias são mais altas. Estes seriam obrigados a reduzir custos.

O novo sistema de pagamento não significou a substituição imediata das diárias uniformes. Em 1997, estimava-se que entre 20\% e 25\% (16-20 bilhões de marcos) das internações hospitalares sejam remuneradas conforme o novo sistema de pagamento. ${ }^{168}$ Em 1997, estavam definidas remuneraçōes para 73 diagnósticos (Fallpauschalen) e para 147 procedimentos especiais (Presseamt, 1997:39).

Não há consenso a respeito do destino do sistema de pagamento hospitalar. A ampliação ou não do catálogo de procedimentos constitui objeto de conflito. As Caixas, com exceção das Locais, exigem imediata ampliação do catálogo de diagnósticos e procedimentos. Os hospitais defendem a manutenção do pagamento de diárias uniformes. As Caixas Locais (AOK) estimam que a ampliação do catálogo de procedimento pode levar ao aumento de gastos e sugere que esta modalidade de pagamento seja restrita a certa percentagem do conjunto das remunerações hospitalares. ${ }^{169}$

\section{Alocação de recursos para o setor hospitalar}

A alocação de recursos para o setor hospitalar, desde 1993, com a Lei da Estrutura da Saúde, passou a ser regulada por lei, tendo-se estabelecido que a evolução dos gastos do setor hospitalar não deveriam ultrapassar a das receitas de contribuição durante os próximos três anos.

Contudo, muitas exceções foram incluídas, o que produziu elevação dos gastos no setor maior do que a evolução da receita do GKV. Em 1996, um teto máximo para os gastos hospitalares com reduções para mais e para menos do valor

167 Como mecanismo para evitar altas precoces e/ou reinternações desnecessárias caso um paciente dê entrada pelo mesmo motivo ou em decorrência de complicação, não há nova remuneração até o limite da permanência normatizada para o procedimento (Vollmer, 1994).

168 Com o decreto federal para as taxas de cuidados hospitalares de 1995, as alteraçōes do sistema de pagamento introduzidas pela Lei da Estrutura da Saúde foram regulamentadas. $O$ novo sistema deveria entrar em vigor, para todos os hospitais, no início de 1996, porém, a implementação foi transferida para 1998, após avaliação da experiência de alguns hospitais.

169 Os conservadores propõem que o catálogo seja elaborado por Caixas e hospitais sem a participação governamental. $\mathrm{O}$ partido social-democrala (SPD) defende diárias diferenciadas por tipo de clínica/enfermaria. 
das diárias conforme a variação dos gastos em relação ao teto para cada hospital foi definido. Teve por base os gastos do ano anterior, acrescidos de taxa correspondente aos aumentos salariais do serviço público (CDU/CSU und FDP, 1995b).

Atualmente, na Europa, o modelo de controle de gastos em saúde mais comum é a definição de tetos orçamentários, sejam estes globais ou por setores de atenção. A prática de controle dos orçamentos hospitalares é difundida na Uniāo Européia: onze dentre os doze países, com exceção da Grécia, controlam os orçamentos hospitalares (Abel Smith, 1996).

Em 1997, foi proposta a definiçāo de tetos máximos estaduais para os gastos hospitalares do GKV. Por meio deste novo mecanismo, e delimitadas por ele, pretender-se-ia estimular inovaçōes setoriais decorrentes da competição entre os hospitais em cada estado. A proposta não foi aprovada, em virtude da discordância das sociedades de hospitais. Em 1999, percentuais máximos, correspondentes à evolução das receitas do GKV para a evolução dos orçamentos de cada um dos hospitais foram novamente definidos por lei.

\section{Percepção de problemas}

Na Alemanha, a profunda separação da atenção hospitalar e ambulatorial e a sua conseqüente falta de articulação têm sido reiteradamente apontadas como importante problema da organização do sistema de atenção como fonte de ineficiências. Esta separação decorreu de interesses profissionais e econômicos da corporação médica e fez com que quase todas as possibilidades terapêuticas estivessem disponíveis igualmente em nível ambulatorial, produzindo ineficiências, visto que a atuação dos médicos de hospital na atençāo ambulatorial é extremamente restringida pelas Associaçōes de Médicos das Caixas.

Na discussão concernente aos setores responsáveis pelos déficits financeiros, destaca-se o setor hospitalar, uma vez que a participação da atenção hospitalar no conjunto dos gastos é a maior e tem aumentado nos últimos anos. O tempo médio de permanência hospitalar, avaliado como muito longo em comparação internacional, é argumento freqüente para apontar ineficiências no setor.

Embora os tempos médios de permanência em comparação internacional sejam altos e possam ser avaliados como campo efetivo de intervenção para maior eficiência, sua redução não terá o impacto por muitos esperado. Schwartz \& Busse (1994) chamam a atenção para o fato de que tempos médios de permanência mais curtos não necessariamente implicam economias na atenção.

Para esses autores, a estimativa de que o tempo mais longo de permanência represente ineficiência do sistema, contribuindo de maneira expressiva para os gastos, e que sua diminuição seria positiva para a atenção funda-se em pressupostos enganosos: 1) encurtamento em um dia do TMP levaria à economia de gastos 
correspondente à diária média; 2) a duraçāo da permanência hospitalar pode ser reduzida, sem que aumentem os gastos do setor ambulatorial; 3) o TMP poderia ser reduzido, sem produzir intensificação dos cuidados e perda da qualidade para os pacientes e familiares.

Estudos recentes realizados nos EUA mostram que os custos médios por dia de internação têm aumentado paralelamente ao encurtamento dos TMP e/ou sido repassados para o setor ambulatorial. A alta precoce gera a necessidade de prestação de número maior de cuidados ambulatoriais pós-internação. ${ }^{170}$ Acarreta ainda sobrecarga dos familiares ou amigos que necessitam revezar-se nos cuidados domiciliares ao paciente, o que nunca é levado em conta na análise de custos. ${ }^{171}$

Por sua vez, o deslocamento de gastos para o setor ambulatorial é bem claro no caso das cirurgias ambulatoriais. Recentemente, inúmeras técnicas menos invasivas têm propiciado a realização de diversos procedimentos nos consultórios médicos, que anteriormente eram prestados apenas em nível hospitalar, o que produz evidente deslocamento de gastos e, ao mesmo tempo, estimula a realização de volume maior desses serviços pelas facilidades que oferecem.

Para os pacientes, a inegável menor invasividade das técnicas cirúrgicas não significa que possam voltar de imediato a suas atividades ou que não apresentem algum grau de dependência, carecendo de cuidados.

A implementação de fortes estímulos ao encurtamento dos tempos de per- manência, dados estes deslocamentos, pode produzir impacto negativo sobre a qualidade da atenção em um sistema no qual os gastos ambulatoriais são estritamente orçados, como foi o caso da Alemanha durante muitos anos.

A redução dos TMP não leva, portanto, à diminuição correspondente do conjunto dos gastos hospitalares, uma vez que os cuidados são intensificados nos dias restantes. Em geral, o mesmo conjunto de exames e procedimentos passa a ser realizado em período menor de dias. Na verdade, a principal economia que pode existir diz respeito aos custos referentes aos serviços de hotelaria correspondentes aos dias de internação cortados, e estes não representam parcela importante dos gastos. Tem sido acompanhada por aumento importante no número de internaçōes; o número total de dias internaçōes, portanto, não se reduz na mesma intensidade.

Para além do debate a respeito do alcance de maior eficiência e contenção de gastos, reformas setoriais são consideradas essenciais à melhoria da qualidade da atenção. Como forma de promover a articulação da atenção ambulatorial e hospitalar e conter custos, foi ampliado o espectro de açōes oferecidas pelos hospitais, ao mesmo tempo em que ações, até então realizadas apenas em regime de internação, passaram a ser produzidas em nível ambulatorial.

170 Para cada dia de internação reduzido é produzido 0,7 contato médico ambulatorial a mais (Schneider et al. apud Schwartz \& Busse, 1994).

171 O encurtamento drástico dos TMP pode ser considerado repasse de despesas para os pacientes no que tange aos cuidados domiciliares e aos medicamentos. 
Com a Lei da Estrutura da Saúde, de 1993, foi introduzida a possibilidade de tratamento pré e pós-internação e regime de internação parcial, assim como a possibilidade de realização de cirurgias ambulatoriais. Cuidados domiciliares pós-internação passaram a integrar também parte do catálogo de serviços do GKV, a fim de reduzir os períodos de internação. 